\title{
Trajectòria artística del dibuixant Pere Ynglada (I88I-I958). \\ De la Belle Époque a la síntesi oriental
}

\author{
Ricard Bru Turull \\ Universitat Autònoma de Barcelona. Departament d'Art i de Musicologia \\ ricard.bru@uab.cat
}

Recepció: 19/09/2018, Acceptació: 26/09/2019, Publicació: 20/12/2019

RESUM

A partir de la dècada de 1920 Pere Ynglada va esdevenir un nom imprescindible i un referent del dibuix animalista a Catalunya. Aquest article indaga en la trajectòria vital i posa èmfasi en les aportacions artístiques d'Ynglada, des dels inicis en temps del modernisme i l'etapa de plenitud viscuda a París, fins als últims anys de la seva vida, de retorn a Barcelona.

Paraules clau:

Pere Ynglada; dibuix; il-lustració; El Guayaba; animals; art de l’Àsia Oriental

\section{Abstract}

Artistic trajectory of the illustrator Pere Ynglada (I 88 II958). From the Belle Époque to the Eastern synthesis

From the I920s onwards, the artist Pere Ynglada became a reference in Catalonia in the field of animal drawing. This article explores his vital trajectory and emphasizes Ynglada's artistic contributions from the beginnings of Catalan modernism and the stage of plenitude in Paris, to the last years of his life after returning to Barcelona.

Keywords:

Pere Ynglada; drawing; illustration; El Guayaba; animals; art of East Asia 
$\mathrm{P}$ ere Ynglada va ser un dels grans dibuixants catalans de la primera meitat del segle xx. Tot $\mathrm{i}$ que resulta fins a cert punt sorprenent la poca atenció que fins avui ha rebut, afortunadament, poc després de morir sense descendència el febrer de 1958 , els seus amics íntims van procurar que el record de l'artista perdurés. Així, alhora que se'n celebrava una gran exposició pòstuma al Palau de la Virreina ${ }^{1}$, Carles Soldevila va treure a la llum el volum Records $i$ opinions de Pere Ynglada, el notari Raimon Noguera va fer una primera donació de dibuixos d'Ynglada al Museu Nacional i els marmessors de l'artista, per voluntat testamentària, van crear la Fundació Ynglada-Guillot amb l'objectiu d'organitzar i gestionar el concurs internacional de dibuix que, amb el mateix nom, ha perdurat fins a l'actualitat ${ }^{2}$.

En morir, Pere Ynglada va deixar la seva obra en mans de quatre bons amics: el seu metge de confiança, el Dr. Benet Perpiñà Robert; el seu notari, Raimon Noguera; el seu soci, Frederic Barris Esteva, i l'escriptor Carles Soldevila. Tots ells van estimar l'artista i van preservar el llegat material i el record del personatge, que també va quedar recollit a la tesi de llicenciatura d'Esther Tusquets, titulada Pedro Ynglada: La expresión de lo fugaz (1960), un dels pocs estudis acadèmics que tenim sobre l'artista, juntament amb un perfil més recent publicat l'any $20 \mathrm{I} 2$ per Francesc Fontbona ${ }^{3}$. Així mateix, al llarg dels anys han anat apareixent algunes altres aportacions puntuals, malgrat que encara està per fer-ne la biografia artística completa ${ }^{4}$. Des d'aquest punt de vista, el present article té com a objectiu esbossar alguns d'aquells punts que considerem més rellevants per comprendre l'aportació de Pere Ynglada.

\section{Els anys de la Belle Époque (1903-1906)}

Sabem, perquè així ho explicava ell mateix, que Pere Ynglada va néixer a Santiago de Cuba l'any I 88 I $^{5}$. Fill d'Artur Ynglada i de Concepció Sallent, tots dos naturals de Vilafranca del Penedès, s'havien establert a les Antilles, on el cosí germà del pare havia obert un establiment de ferreteria. Allà va ser on Ynglada va passar la seva infància, amb algun viatge a Nova York $\mathrm{i}$ amb algunes anècdotes vora els seus germans i la seva dida Elisa que recordaria al llarg dels anys ${ }^{6}$.

Jaume Mercader-Miret, que pocs mesos abans de la mort de Pere Ynglada es va poder entrevistar amb l'artista, anotà que va ser l'any I 887 quan la família Ynglada Sallent va tornar de Cuba a Vilafranca del Penedès, ciutat on el jove Ynglada es va integrar ràpidament. Ell sempre va recordar una joventut lligada a Vilafranca, on el pare va obrir un negoci de ferreteria (Arturo Ynglada y Cía) similar al que havia regentat a Cuba i on el fill va fer els primers passos com a dibuixant freqüentant l'acadèmia del pintor Ricard Clausells'. En efecte, el primer testimoni d'aquests inicis el tenim el setembre de i90 i en ocasió de l'Exposició Comarcal de Vilafranca, en la qual Arturo Ynglada y Cía va muntar un estand propi al saló de la Lliga Industrial i Comarcal. El pare, però, no hi va participar en solitari, sinó que, donant suport a l'entusiasme que el seu fill Pere demostrava ja aleshores pel dibuix, el va animar a intervenir-hi com a artista exposant diversos dibuixos vora un conjunt d'obres aportades per l'Acadèmia de Belles Arts: «una colección de dibujos que á pesar de ser su autor casi un niño, don Pedro Inglada Sallent, revelan una mano de maestro» ${ }^{8}$. 
Josep Pla, amb qui Ynglada va compartir una amistat duradora, va voler posar un èmfasi especial en la importància vital que va tenir pel jove artista el negoci familiar de ferreteria'. La semblança que ens n'ofereix Pla ens el presenta com un antibohemi reservat, introvertit, discret $i$ ben vestit, com tots els noucentistes, un home d'una gran correcció i pulcritud que sempre va saber mantenir el seu doble vessant, com a persona de negocis i com a artista exigent. Era, deien, un gentleman que, a parer d'alguns, defugia l'habitual esnobisme dels connaisseurs ${ }^{10}$. Aquest apunt és important en tant que al llarg dels anys la ferreteria familiar va esdevenir la font principal d'una fortuna i d'una abundància econòmica que li van permetre viure folgadament, gaudint de l'art i d'una vida burgesa sense haver-se de preocupar mai dels diners, ni per haver de vendre, ni d'exposar. Així, va començar treballant com a ajudant de l'establiment d'Arturo Ynglada y Cía i, després de la mort del pare el maig de 1908, va afegir-se amb el seu germà Artur a la direcció del negoci de Sucesores de Arturo Ynglada y Cía, compartit amb el soci Frederic Barris Clascar, que, com a gerent de l'empresa, portaria la gestió d'un nou establiment de prestigi obert a la Rambla de Catalunya, número 22, amb el nom de Dos Leones ${ }^{11}$. Ynglada va implicar-se amb el negoci familiar viatjant per Europa per seguir tendències i a la recerca de nous productes, però amb la llibertat de poder mantenir, en paral.lel, una vida d'artista $^{12}$. Així és com aquell I90I, un cop presentats els seus primers dibuixos a Vilafranca, el pare el va enviar a Alemanya per completar la formació en el ram de la ferreteria.

Pere Ynglada va viure a Alemanya, a Reimsheid, durant uns dos anys, on va tenir ocasió de descobrir revistes del seu interès - per exemple, Jugend - i visitar ciutats com ara Colònia, Düsseldord, Bonn i Berlín, algunes de les quals, segons l'Auca (1913) d'Ismael Smith i Alfons Maseras, acompanyat del seu amic Lluís Garriga $\operatorname{Roig}^{13}$. Amb tot, cap a mitjan 1903 es va traslladar a París, des d'on va continuar viatjant amb en Garriga per França i on va iniciar la carrera artística seduit per la vida de la Belle Époque, les imatges de Le Rire i l'estètica triomfant de Toulouse-Lautrec, Steinlen i Grün ${ }^{14}$. Les ganes d'illlustrar aquest món de festa i plaers el van animar ràpidament a enviar els primers dibuixos per ser reproduits en revistes barcelonines. És així com la revista ; $\mathrm{Cu}$-Cut! va publicar, amb data de 20 d'agost de 1903 , la primera il-lustració d'Ynglada a París, un dibuix de sàtira a les modes impostades $i$ estrafolàries de portar barrets. Aquest va ser l'inici d'un èxit fulgurant que el va dur a convertir-se, en els dos anys següents, en un dels principals dibuixants

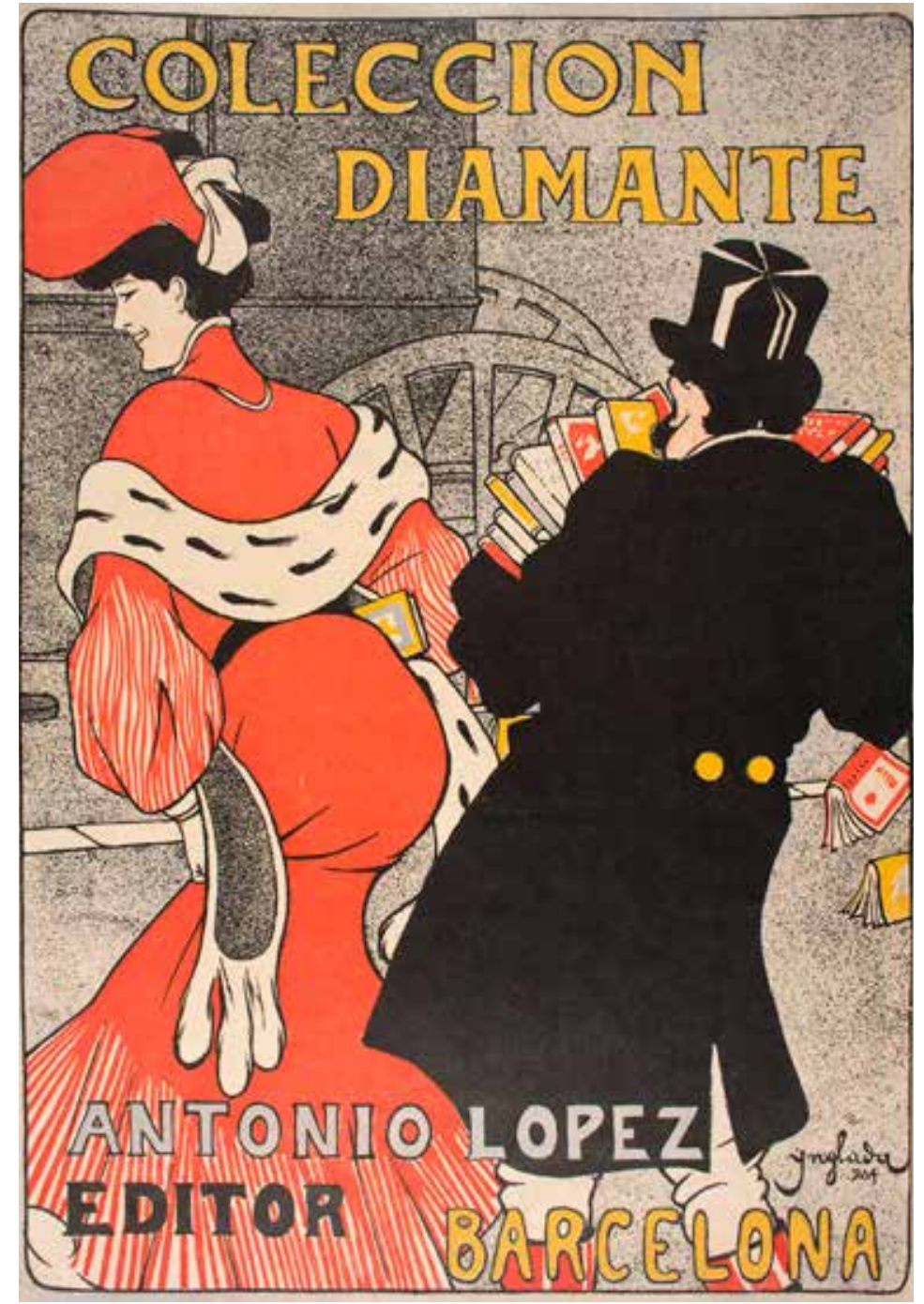

Figura 1.

YDA (Pere Ynglada), Colección Diamante - Antonio López editor, 1904. Litografia, 38,2 x 26,5 $\mathrm{cm}$. Museu Nacional d'Art de Catalunya, 2.946-C. Fons antic del Gabinet de Dibuixos i Gravats.

de les revistes il-lustrades de Barcelona. Amb el suport de l'editor Antonio López (figura I), tan sols entre el mes de gener de 1904 i de desembre de 1905 , Ynglada va arribar a enviar més de dues-centes il-lustracions que van aparèixer repartides entre ; $\mathrm{Cu}$-Cut!, Calendari ; $\mathrm{Cu}$-Cut!, La Esquella de la Torratxa, l'Almanach de La Esquella de la Torratxa, La Campana de Gracia i l'Almanach de La Campana de Gracia'15.

Els inicis d'Ynglada com a il-lustrador cal situar-los entre París i Barcelona, i és que si bé és cert que els primers dibuixos estan datats a la capital francesa l'any 1903, bona part de les illustracions van ser fetes a Barcelona i mostraven unes temàtiques d'acord amb la realitat social catalana del moment (figura 2). De fet, l'anàlisi de les il-lustracions i les postals que enviava, així com l'observació de la signatura de l'artista, que firmava amb el pseudonim Yda, a més dels seus propis records, ens permet afirmar que Ynglada 


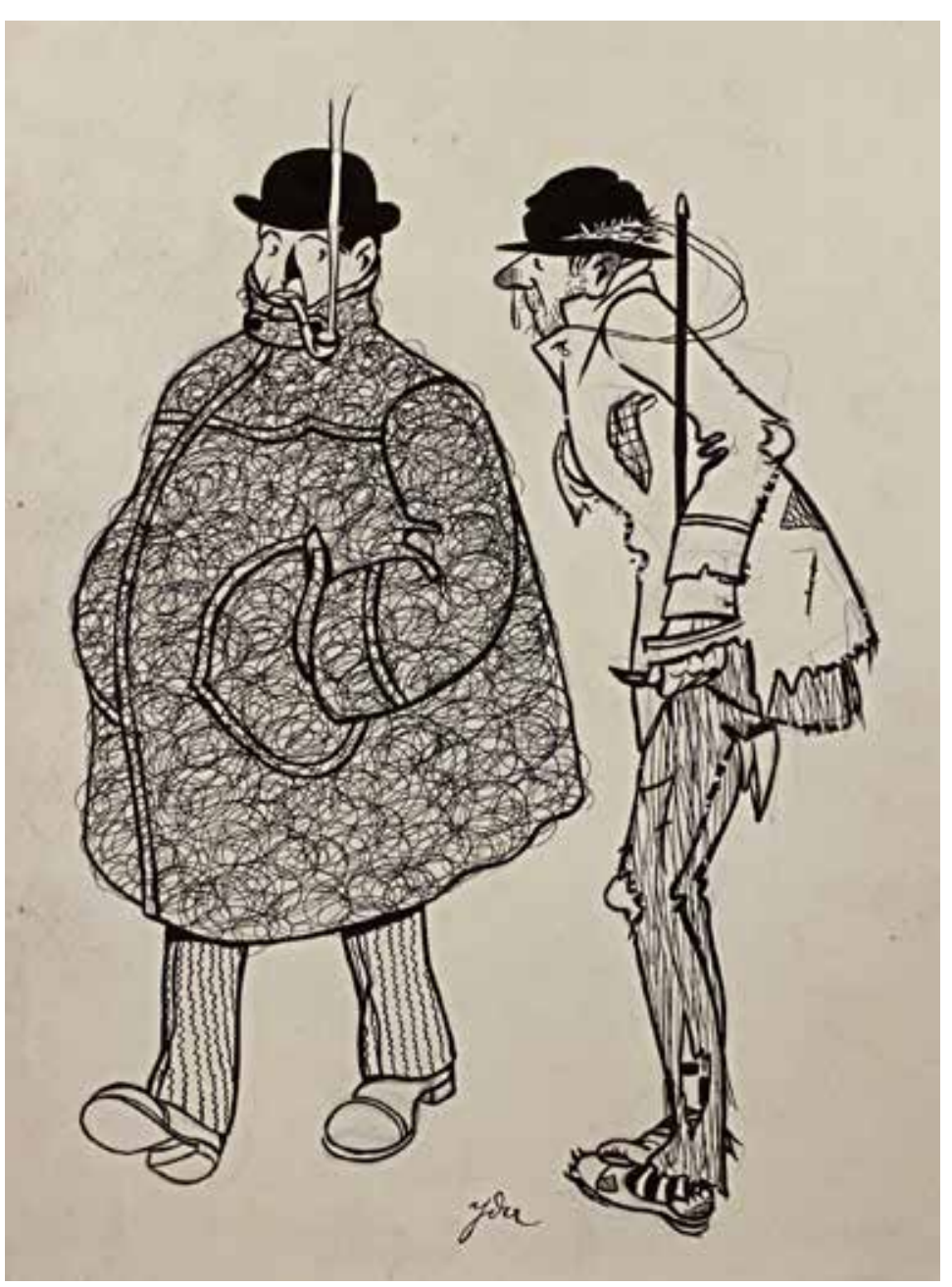

Figura 2.

YDA (Pere YNGLADA), dibuix Uns tant y altres tan poch, reproduï a La Esquella de la Torratxa el 13 de gener de 1905. Museu Nacional d'Art de Catalunya, 85.650. Adquisició col·lecció Agell, 1962.
París l'any i905 als seus companys, com ara la imatge de La Gioconda, que sempre va fascinar Ynglada pel paisatge del fons, que, a parer seu, era «rigorosament una pintura xinesa» ${ }^{20}$. De la mateixa manera que es conserven algunes notes i fotografies de r905 de Pere Ynglada treballant encara a El Guayaba, durant els mesos de juliol, setembre i novembre Ynglada va signar cinc dibuixos des de París, el 2 I juliol en signà un des de Boulogne-sur-Mer, mentre que tant al juny com al setembre, al novembre $i$ al desembre va publicar a La Esquella de la Torratxa dibuixos de temàtica local barcelonina. En altres paraules, sembla com si la marxa a París hagués estat progressiva, fruit d'una necessitat creixent: tot sembla indicar que Ynglada va començar a viatjar amb freqüència a la capital francesa, on al cap de poc es va acabar establint delerós d'aprendre ${ }^{21}$. En tot cas, l'activitat continuada com a il.lustrador i cronista gràfic de la vida urbana i burgesa barcelonina i francesa van acabar tenint la seva primera manifestació notòria amb la celebració d'una exposició conjunta amb Ismael Smith l'estiu de 1906 a la Sala Parés.

Entre els dies r 6 i 30 de juny de I906, la Sala Parés va presentar una selecció de vuitanta dibuixos d'Ynglada i diverses escultures en porcellana d'Ismael Smith, entre els quals s'hi trobava la Rosa mística (ca. I905-I906). En el cas d'Ynglada, els dibuixos eren majoritàriament inèdits i fets durant els mesos anteriors d'estada a París, amb temàtiques eminentment franceses que van tenir ressò a la premsa (figura 3). Ynglada va ser elogiat pels crítics més fidels per uns dibuixos que eren similars als que aleshores feien Junceda i Opisso, i que seguien de manera mimètica l'estil $\mathrm{i}$ les temàtiques de revistes humorístiques il-lustrades de referència, com ara Le Rire i Le Frou-Frou, però al mateix temps també va ser criticat per mostrar una obra amb poc caràcter: «me fa l'efecte que l'autor s'hauria de capificar més en ferse una personalitat propia, ab lo qual hauria conseguit dirnos quelcom més de nou que no's ha dit», apuntava J. B. Fécit ${ }^{22}$. En aquesta mateixa direcció, des de Joventut es lamentava el camí emprès els últims mesos: «temps enrera, si bé menys traçut que ara, se'ns havia presentat més personal» ${ }^{23}$. Malgrat la qualitat dels seus dibuixos, els crítics no anaven errats en aquella mirada que el mateix Ynglada va acabar comprenent: "Allò no era per mi. Reconec que havia equivocat el camí» ${ }^{24}$.

L'exhibició a la Sala Parés, qualificada uns quants anys més tard pel mateix Ynglada com «una exposició deplorable» ${ }^{25}$, va marcar un abans i un després en la trajectòria de l'artista. Acabada la mostra, va tornar cap a França i es va establir a París, aleshores ja d'una manera estable, on ben aviat va començar a veure els 
fruits de la recerca d'una expressió artística pròpia capaç de mostrar les seves inquietuds. L'activitat com a il-lustrador es va reduir de manera substancial, no només pels compromisos associats al negoci de ferreteria que compartia $\mathrm{amb}$ el seu germà Artur i amb Frederic Barris, sinó especialment per la descoberta de nous referents artístics.

\section{La recerca d'un art sincer (1907-1920)}

Si a inicis de 1906 La Esquella de la Torratxa encara publicava notes parisenques de cafès concert, bars i espectacles com els del Bal Tabarin seguint el referent de Toulouse-Lautrec, un cop conclosa l'exposició de la Sala Parés, i de retorn a França, durant la resta de l'any només va enviar tres il-lustracions, una des d'Ostende i dues més des de París. Tenia intenció de participar a l'Exposició Internacional d'Art (I907) $\mathrm{i}$ enviar algunes il-lustracions a l'efímera revista Or $i$ grana, "per quedar be ab l'Apa ${ }^{26}$, deia, però no va arribar a fer ni una cosa ni l'altra ${ }^{27}$. La primavera de 1909 va presentar dos dibuixos al Salon des Humoristes que organitzava Le Rire $^{28}$, però la davallada clara i substancial de dibuixos a les revistes il-lustrades es va acusar durant els anys següents, fins a la publicació, el gener de I910, dels dos últims dibuixos d'Ynglada a La Esquella de la Torratxa. En paral-lel, entre novembre de 1908 i maig de 1909 , va afegir-se al grup d'il-lustradors de la revista Papitu, però amb un estil diferent del d'anys anteriors, molt més pròxim a la moda nova francesa. En definitiva, Ynglada va optar per renunciar a la caricatura i a l'aura modernista per començar a depurar el dibuix abandonant qualsevol traça de color. Va ser un procés de síntesi de les formes, eliminant els fons de figures que van ser actualitzades a partir d'uns traços de pinzell cada cop més segurs (figura 4).

A partir de 1907, Ynglada es va establir al carrer Rodier, on poc després va passar a viure amb la seva esposa, Georgette Guillot Flinois, a poca distància d'un taller propi, al carrer Des Martyrs ${ }^{29}$. Ynglada, acompanyat sempre que podia del seu buldog francès $S_{n o w}^{30}$, va començar a descobrir París, parcs, teatres, circs, museus, salons i altres espais d'art, com ara el Cercle Volney, de manera que aviat va deixar enrere les imatges dels cartells publicitaris de Montmartre que tant l'havien marcat de jove i que van començar a ser substituïdes per clowns, jocs d'acrobàcia, siluetes femenines, zebres $\mathrm{i}$ cavalls ${ }^{31}$. El canvi es va produir sense ànsia $\mathrm{i}$ sense presses a partir de 1907-1908, en veure's seduït per l'art oriental, descobert inicialment

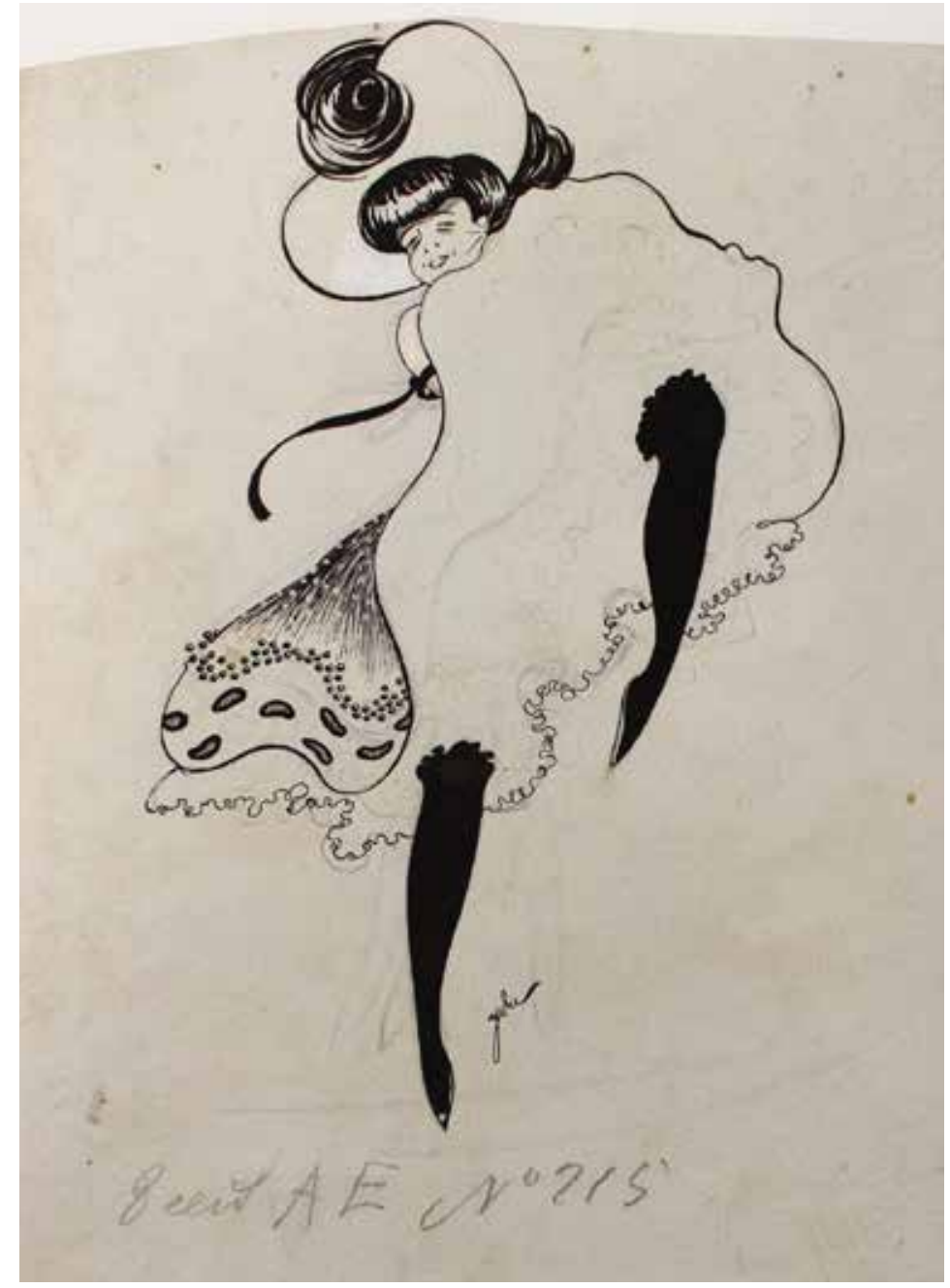

Figura 3.

YDa (Pere Ynglada), Mademoiselle Tabalot. Dibuix reproduït a l'Almanach de la Esquella de la Torratxa de 1905. Museu Nacional d'Art de Catalunya, 85.699. Adquisició col-lecció Agell, 1962.

al Museu Guimet, juntament amb Josep Maria Junoy, i al Museu Britànic, a la primera visita a Londres, l'any 1908. Com veurem més endavant, seguint les passes de Degas, l'art japonès i xinès van significar una revelació per Ynglada, de la mateixa manera que les llargues hores al Jardí d'Aclimatació de París van obrir-li un nou món: «un dia vaig anar al Jardí de Plantes, on sabreu que hi ha installlada la colllecció zoològica, i vaig trobar un nou camí: els animals. Des de llavors dibuixar animals fou cosa que m'apassionà» ${ }^{32}$.

En parallel a les visites constants a Barcelona, entorn dels membres de la penya de l'Ateneu hereva de les trobades al Guayaba, Ynglada va començar a fer des de París diverses incursions a vessants artístics que fins aleshores no havia explorat ${ }^{33}$. D'una banda, segons informava La Esquella de la Torraxta el juny de i9 I en ocasió d'una visita d'Ynglada a la ciutat, aquest es preparava per fer «una magna exposi- 


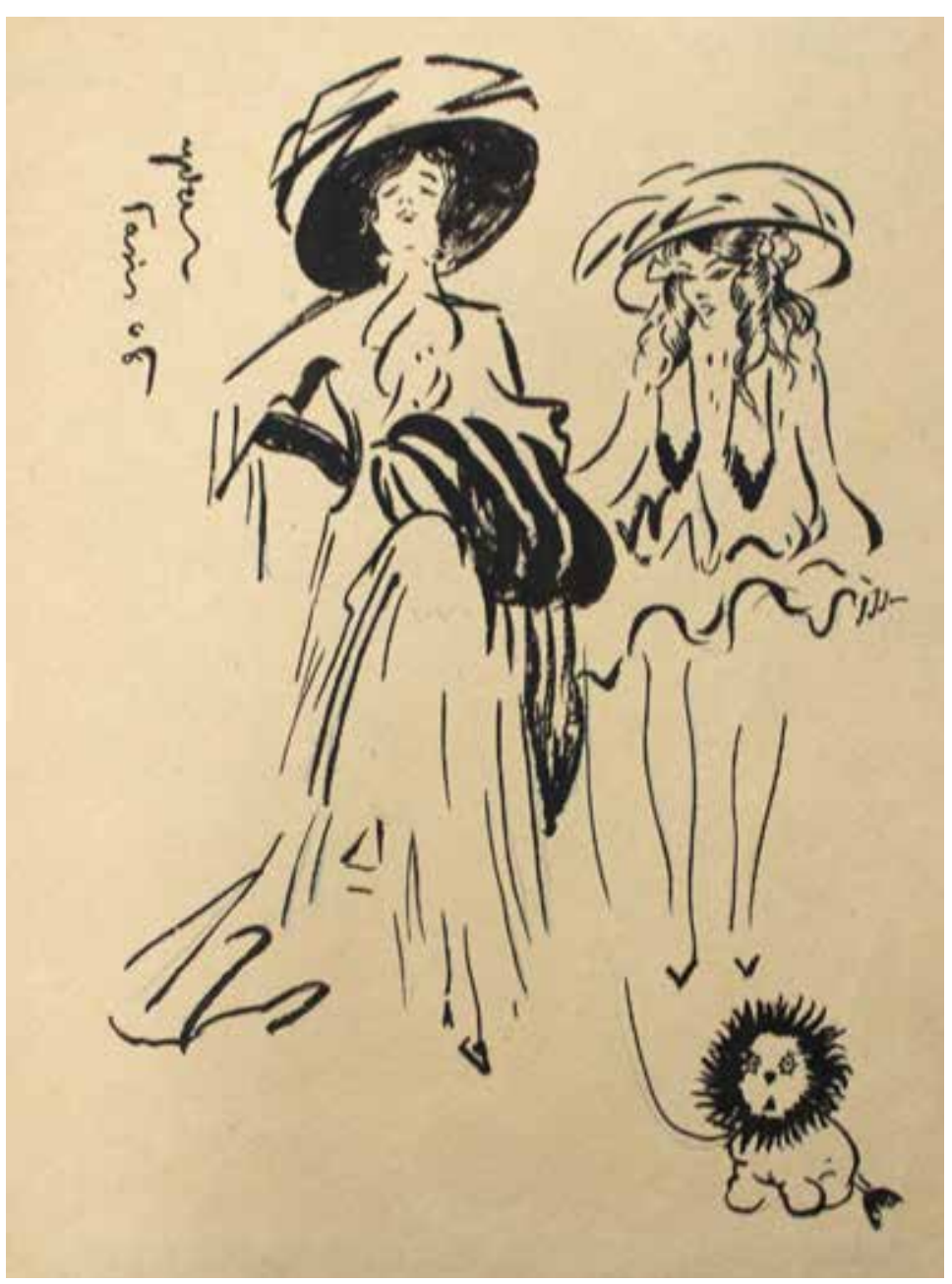

Figura 4.

YDA (Pere YNGLADA), dibuix Les enfants terribles, reproduit a La Esquella de la Torratxa el 28 de febrer de 1908. Signat "Yda Paris 08». Museu Nacional d'Art de Catalunya, 85.675. Adquisició col-lecció Agell, 1962. ció de dibuixos (aiguaforts) [sic]"34, notícia que, sense tenir més ressò, va tornar a aparèixer al cap d'un any a les pàgines de La Publicidad: «a fines de invierno, Pedro Inglada es probable que exponga en el Fayans algunas de sus litografias y aguafuertes» ${ }^{35}$. La dada, confirmada per Junoy l'any i9r 2 en afirmar que Ynglada acabava d'imprimir una sèrie de litografies i aiguaforts amb escenes de circ i de music-hall ${ }^{36}$, és especialment interessant, perquè no coneixem cap testimoni d'aquesta aproximació a l'art del gravat, i únicament s'han pogut documentar dues obres a l'exposició que celebraria l'any I9I4. D'altra banda, compaginant l'assistència continuada al món dels espectacles musicals i de circ, Ynglada va mostrar-se receptiu i obert al present per estar al dia i sumar-se, des d'una mirada personal, a alguns dels nous corrents artístics del moment. És així que es va interessar tant per l'art cubista, descobert l'any i9 Io juntament amb Josep Dalmau i Ismael Smith al Salon d'Automne, com també pel naixement de la revista Picarol, impulsada l'any i 9 I 2 per Santiago Segura ${ }^{37}$, per, pocs anys més tard, participar a l'exposició Art Nou Català (I9I s) de Sabadell $i$ afegir-se al grup de Les Arts i els Artistes. En aquest camí, el dibuix d'Ynglada es va anar perfilant amb notes preses a estudi, nus femenins, retrats d'amics propers (figura 5), espectacles $\mathrm{i}$ escenes naturals, i l'evolució de la seva obra, virant del modernisme cap al noucentisme, es va acabar fent pública al Faians Català el maig de I9I4 en la primera i única exposició individual que va celebrar en vida.

Amb data de is de maig de i9i4, coincidint amb l'obertura de l'exposició Ynglada, Eugeni d'Ors presentava l'artista des de la tribuna que li oferia el Glosari, que havia anat publicant des de feia uns quants anys a La Veu de Catalunya. El títol de la glossa, Pere Ynglada, noucentista ${ }^{38}$, permetia sumar-lo a la llarga llista de personatges que havien d'acabar configurant, a parer seu, l'ideari noucentista, com Laura Albèniz, Josep Maria Sert, Pere Torné Esquius o Enric Casanovas. Ynglada presentava un conjunt d'obres format per dotze dibuixos acolorits, setanta-tres dibuixos sense color (figura 6), un aiguafort $i$ una punta seca. Un total de vuitantaset peces que revelaven un artista diferent del que els barcelonins havien conegut vuit anys abans a la Sala Parés. Presentava pierrots, homes i dones de circ, dones nues, atletes i, sobretot, dibuixos d'animals. Tots eren el testimoni de com Ynglada havia madurat de la mà d'un dibuix honest, de tècnica segura amb llapis, ploma i pinzell. En definitiva, eren obres nascudes principalment de les visites freqüents al Jardí d'Aclimatació de París per observar-hi els animals, des de flamencs i pelicans fins a ovelles, micos, antílops i l'Snow; dibuixos que es presentaven com a instantànies que mostraven una percepció delicada i aguda de la vida íntima de la natura similar a la d'alguns dibuixos de Pisanello que Ynglada tenia reproduits a la seva biblioteca $^{39}$. A diferència del que havia succeït l'any I906, aquesta vegada la premsa va mostrar un elogi gairebé unànime ${ }^{40}$.

Amb Jules Renard, Pisanello, Delacroix, Degas, Hokusai, l'art oriental i els impressionistes com a nous referents, Ynglada va passar pàgina, va deixar definitivament endarrere les imatges de la Belle Époque per centrar-se de manera quasi exclusiva $i$ persistent a temes naturals tractats de manera exquisida a partir d'un dibuix precís i depurat que els crítics ja interpretaven com el reflex d'una expressió oriental $^{41}$, a la manera d'un «japonisme modern» que l'artista hauria d'aprendre a dominar i controlar, deia Joan Sacs ${ }^{42}$. En aquest camí incipient, però, Ynglada feu un parèntesi marcat per l'experiència bèl-lica de la primera Guerra 
Mundial, que el va trasbalsar en plena activitat artística obligant-lo a aturar-se de nou: «tot el treball començat amb l'exposició que us he dit de l'any I 4 quedà estroncat ${ }^{43}$.

Amb l'inici de la Gran Guerra, i contra el que s'havia proposat, Ynglada va retornar al món de la il.lustració gràfica, però ho va fer amb una determinació clara $\mathrm{i}$ amb un caràcter diferent a través de la revista francòfila Iberia, on, entre el mes de maig de igis i el mes de desembre de 1918, van aparèixer, alternats amb els de l'Apa, nombrosos dibuixos seus. El compromís d'Ynglada amb França i la defensa del front aliat es va fer palès de manera continuada en més d'una vuitantena de dibuixos en els quals el dolor i el patiment s'alternaven amb l'experiència viscuda com a reporter gràfic al front de guerra. El mateix Ynglada va ser prou clar a l'hora d'explicitar el que el va motivar a tornar a la il-lustració de revistes: "pour la defense de la France et combattre la propagande germanophile» ${ }^{44}$. Eren dibuixos que transportaven l'espectador cap als sentiments i els ideals de l'artista, en els quals s'hi evocaven referents de la història de l'art. S'hi podien trobar referències estilístiques i formals a obres com ara els gravats dels Desastres de la Guerra, de Goya, la Rue Transnonain, le is Avril I834, de Daumier (figura 7), els Ballets Russos, de Diaghilev, o fins i tot l'escultura futurista Formes uniques de continuitat en l'espai (1913), de Boccioni ${ }^{45}$. La sèrie va concloure a finals de I9I $8 \mathrm{amb}$ dues il.lustracions publicades a La Publicidad i amb alguns dibuixos més que finalment no van ser editats i que van quedar en mans de l'artista ${ }^{46}$.

Tot i que aquesta sèrie de dibuixos ha romàs pràcticament oblidada, va tenir una gran difusió $i$ un ressò molt important a l'època, va ser elogiada poc abans de morir per Rémy de Gourmont des de les pàgines de La France i per André Blum a la Gazette des Beaux-Arts, alhora que molts dels seus dibuixos, juntament amb els d'Apa, van ser seleccionats per formar part de l'àlbum Germania, publicat a París a finals de $1916^{47}$. I és que Ynglada, com a membre actiu del Comitè d'assistència voluntària catalana que lluitava per França, es va implicar de manera plena amb la guerra: el mes de gener d'aquell I9I6 Iberia va publicar unes notes il-lustrades de la seva experiència al front de guerra situat entre Épernay i Reims. Al juliol, Iberia anunciava la pròxima presentació d'un àlbum amb els dibuixos d'Ynglada prologat per Miguel de Unamuno, mentre que al febrer de l'any següent va participar amb l'obra L'embosquée a l'exposició a favor dels legionaris espanyols celebrada a les Galeries Laietanes ${ }^{48}$. En aquest mateix sentit, el desembre de I9I 7 l'artista, acompanyat de Josep Maria Junoy, Josep Clarà i Jaume Brossa,

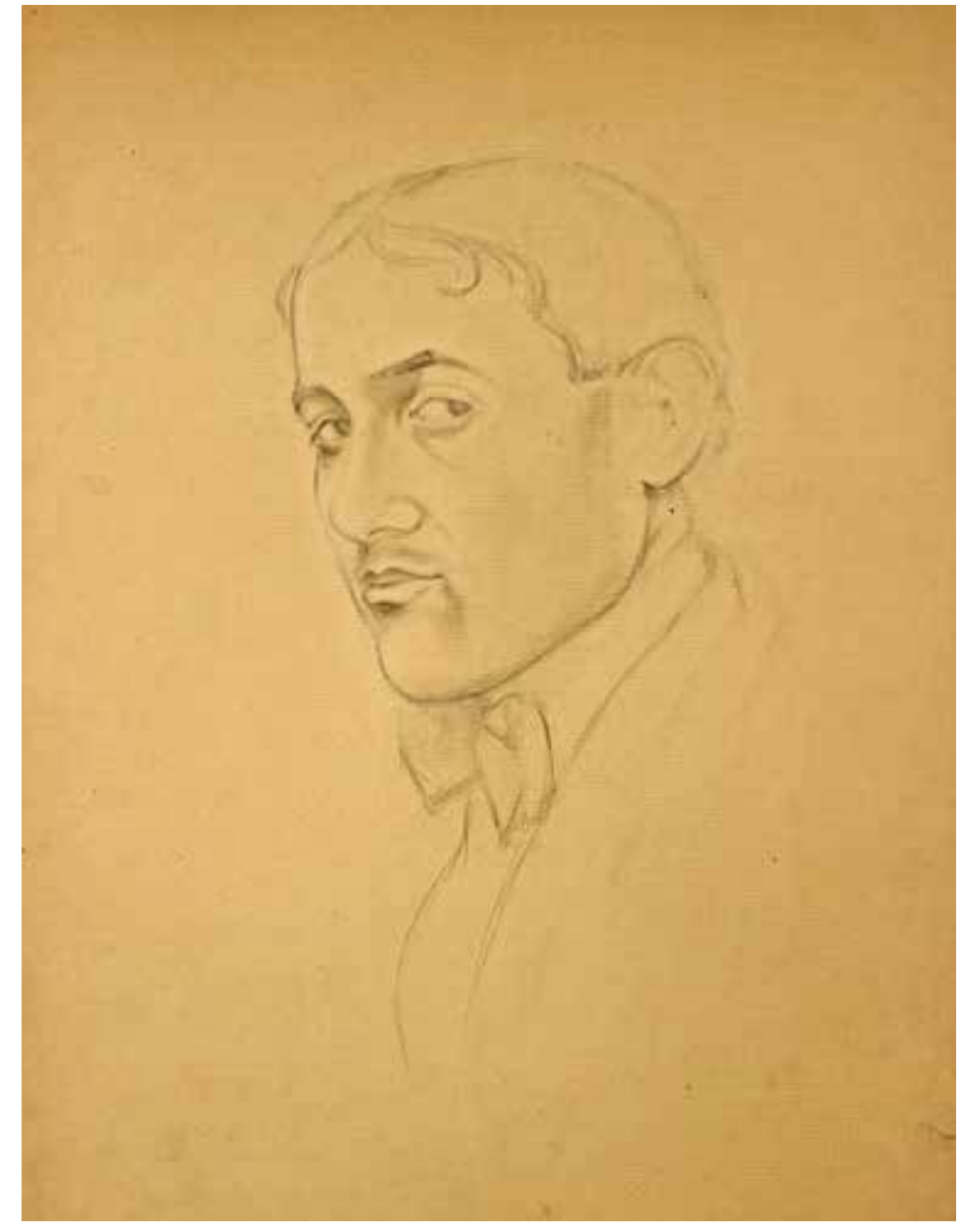

Figura 5.

Pere Ynglada, Retrat d'Ismael Smith, ca. 1911-1912. Museu Nacional d'Art de Catalunya, 157.832. Llegat Raimon Noguera, 1991.

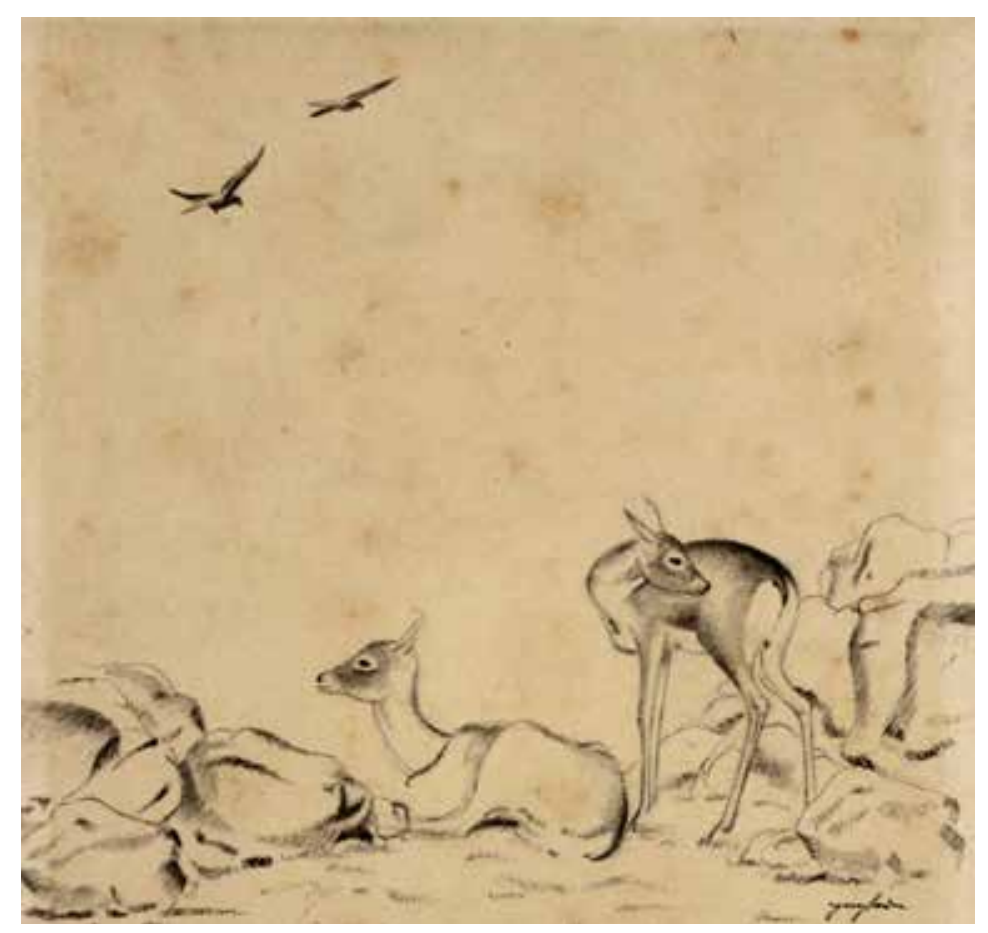

Figura 6.

Pere Ynglada, Antílops entre roques, ca. 1910-1914. Dibuix presentat al Faians Català l'any 1914. Museu Nacional d'Art de Catalunya, 50.595. Llegat Lluís Garriga Roig 1940, ingrés 1953. 


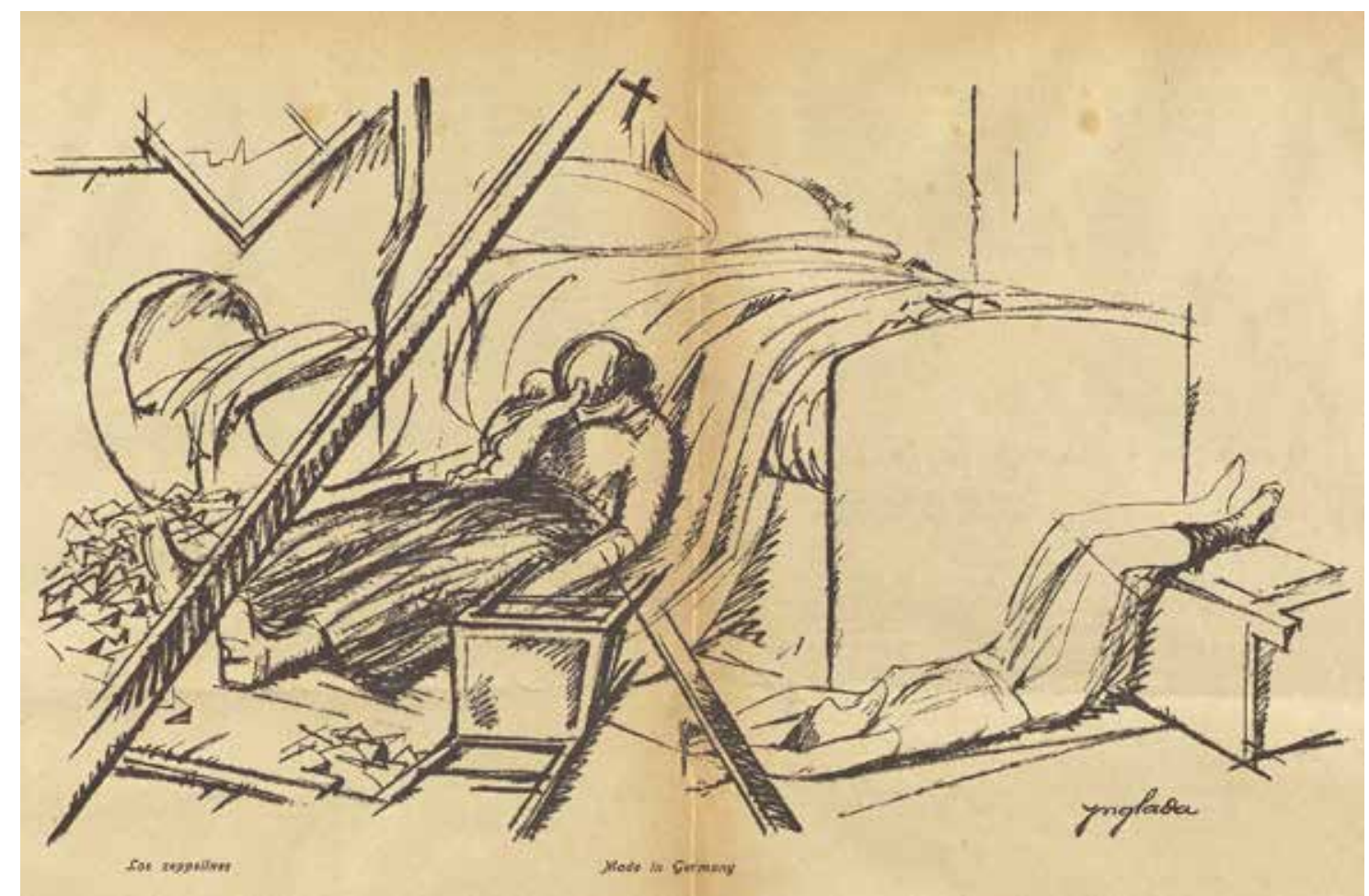

Figura 7.

Pere YNGLAda, dibuix Los zeppelines - Made in Germany, reproduï a Iberia el 12 de febrer de 1916. Biblioteca de Catalunya.

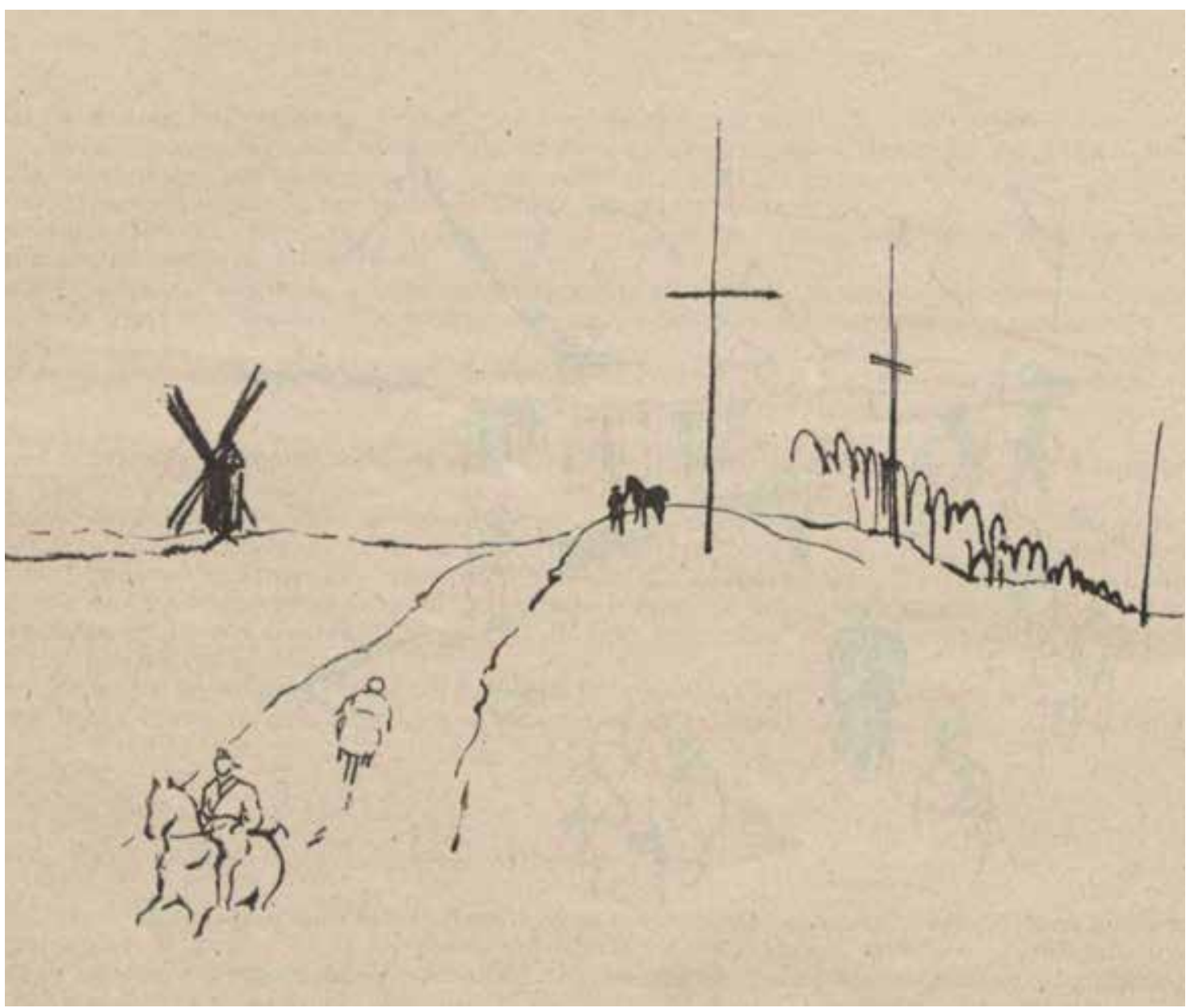

Pere Ynglada, dibuix publicat amb el títol En el frente Británico. Impresión de ruta a la revista Iberia el 30 de març de 1918. El dibuix original es conserva al Museu Nacional d'Art de Catalunya, 157.947. Llegat Raimon Noguera, 1991. 
va entregar al mariscal nord-català Josep Joffre l'àlbum de dibuixos que li havien dedicat els artistes catalans, i encara el març de I9I 8 Iberia va presentar notes d'una nova visita a la zona d'exèrcits, en aquesta ocasió acompanyat d'Eugeni Xammar, Romà Jori, Màrius Aguilar i Claudi Ametlla al front britànic situat al Pas de Calais (figura 8$)^{49}$. Ynglada va tenir ocasió de visitar Georges Clemenceau i als generals Amédée Henri Guillemin, Charles Mangin, Auguste Hirschauer i Henri Gouraud ${ }^{50}$. Amb tot, Ynglada va alternar visites al front amb estades a París, a Suïssa i amb una residència més estable a Barcelona que li va permetre estar al cas tant de l'evolució política i bèl-lica com de les diverses aportacions artístiques del moment: «totes les curiositats de la història artística li han sigut igualment picantes i gustoses», escrivia Joaquim Folch i Torres ${ }^{51}$. En conseqüència, Ynglada es va mantenir actiu com a dibuixant fent, fins i tot, alguna incursió a l'avantguarda, com van ser les il-lustracions publicades per la revista Troços entre 1916 i 1917 (figura 9) ${ }^{52}$. Van ser, en definitiva, uns anys d'exploració que el van conduir, acabada la Primera Guerra Mundial, a la maduresa com a artista.

\section{Devoció per l'art oriental}

En el camí traçat per Ynglada des de la Sala Parés fins als dibuixos animalistes del Faians Català $\mathrm{i}$ als de tinta xinesa dels anys vint, cal situar-hi, com a element determinant $i$ com a punt d'inflexió, la descoberta de l'art de l'Àsia Oriental a partir de l'any 1907: «la descoberta dels extrem-orientals va ésser una festassa», recordava Maseras $^{53}$. Així ho confirmava el mateix Ynglada en una conversa privada mantinguda amb Josep Navarro Costabella: «Quin "souvenir" més agradable la descoberta del Museu Guimet, feta amb ell [Josep Maria Junoy]. És clar que el Museu Guimet era prou conegut; però per nosaltres, i encara particularment per mi, fou una descoberta d'alta importància. Fou el que determinà en mi la passió per l'art extremoriental $\aleph^{54}$. L'impacte definitiu el va tenir l'any següent en ocasió del seu primer viatge a Londres, on, gràcies a la incipient relació amb Charles Vignier, prestigiós antiquari, colleccionista i estudiós de l'art oriental, Ynglada va ser rebut pel cap de les col-leccions asiàtiques del British Museum, Arthur Waley: «va ordenar que col-loquessin davant els meus ulls tot el que jo desitjava veure de pintura i gravats xinesos $»^{55}$. Els resultats d'aquella descoberta es van fer visibles poc temps més tard: l'any I9I I una nota anònima de La Esquella de la Torratxa ja presentava Ynglada com «el més japonès dels

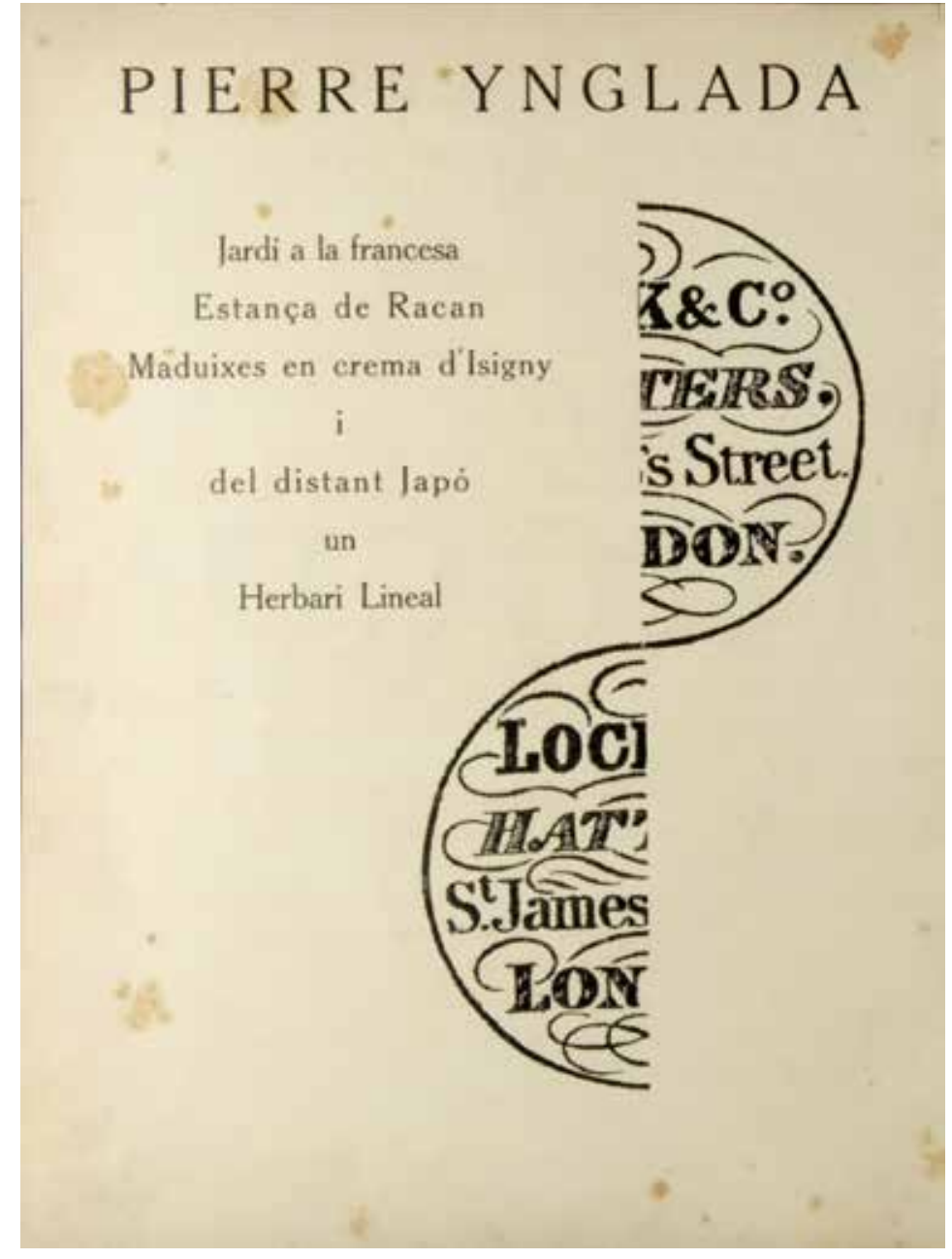

Figura 9.

Pere Ynglada, Troços, primera sèrie, 1916. Biblioteca de Catalunya.

simplificadors de la forma $»^{56}$, mentre que l'any següent Junoy destacava la manera com Ynglada va cultivar, durant el que anomenava com el seu període impressionista, «el género sie-y, croquis rápidos que, con algunas atrevidas pinceladas, dan la visión sumaria del objeto ${ }^{57}$. Dos anys després, Eugeni d'Ors el va glossar a $\mathrm{La}$ Veu de Catalunya i al catàleg de l'exposició del Faians Català, emmirallant-lo en els dibuixos de Hokusai i en les sàvies paraules que l'artista japonès va adjuntar als 75 anys als tres volums de Cent vistes del mont Fuji (1835) ${ }^{58}$.

Fins aleshores la influència japonesa s'havia fet palesa en les primeres il-lustracions d'Ynglada de manera indirecta, a partir de l'aplicació dels models dels postimpressionistes i la tradició gràfica del tombant de segle. Enquadraments originals, formats allargats, superfícies de color pla, així com temàtiques extretes dels gravats ukiyo-e o bé l'evocació freqüent dels tòpics d'Orient motivats per la guerra russo-japonesa van fer que Ynglada sucumbís a la gran onada del japonisme que va recórrer tot Europa ${ }^{59}$. 


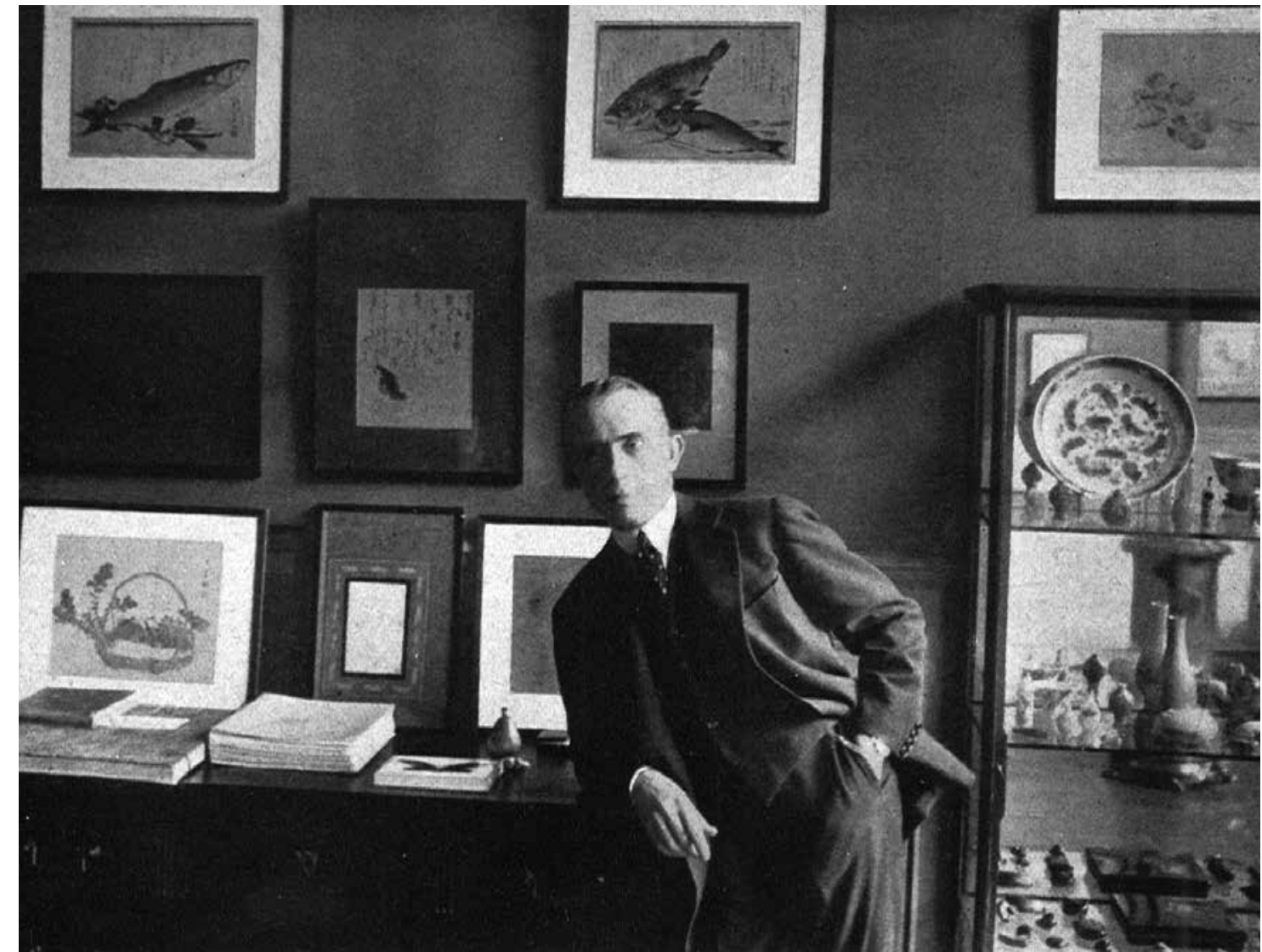

Figura 10.

Pere Ynglada al seu estudi, acompanyat de la collecció d'art persa, xinès i japonès que va anar formant al llarg dels anys a París. Al fons hi apareixen dues estampes d'Utagawa Hiroshige d'una sèrie sense títol dedicada als peixos (ca. 1832-33). Fotografia Serra reproduïda l'any 1934 a la revista Ford.

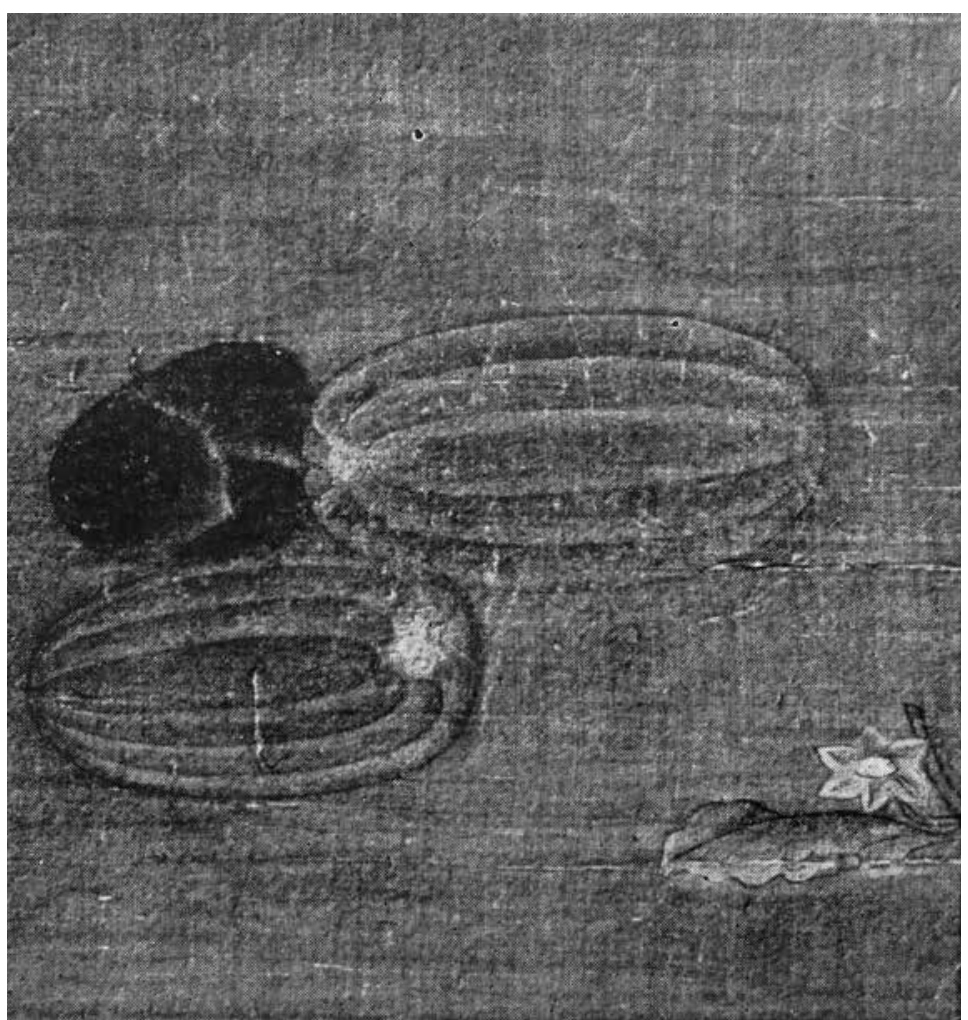

Figura 11.

Qian Xuan, Cogombre i alberginia, finals del segle XIII. Pintura sobre seda. Antiga collecció de Pere Ynglada.
Tanmateix, la descoberta de l'art xinès i japonès de les grans colleccions franceses i angleses, com les de Georges Emorfopoulos, Jacques Doucet i Henry Vever, li va obrir les portes cap a un camí diferent en el qual havia estat treballant entre 1907 i $1914^{60}$.

Superat el parèntesi que va significar la Primera Guerra Mundial, les referències dels crítics i del mateix Ynglada a l'art oriental van passar a ser constants per definir un dibuix que va prendre caràcter propi a partir de l'aprenentatge que li va oferir la pintura monocroma en tinta xinesa, que, en última instància, passaria pel sedàs de la mirada i la sensibilitat de l'artista. L'agudesa, la precisió i l'austeritat del traç, així com l'ús de les gradacions del negre fruit del domini del pinzell, confluien en la representació d'escenes eqüestres preses als hipòdroms de Longchamp i d'Auteuil, com també als camps d'entrenament de la Maison Laffitte i de Chantilly ${ }^{61}$. Així, passada una dècada de les primeres visites al Museu Guimet $i$ al Museu Britànic, les noves coneixences i les visites continuades a exposicions organitzades a França, com la que el Museu Cernuschi va dedicar el 1922 a "Les animaux dans l'art chinois», van convertir Ynglada en un bon coneixedor de les principals col-leccions d'art de l'Àsia Orien- 


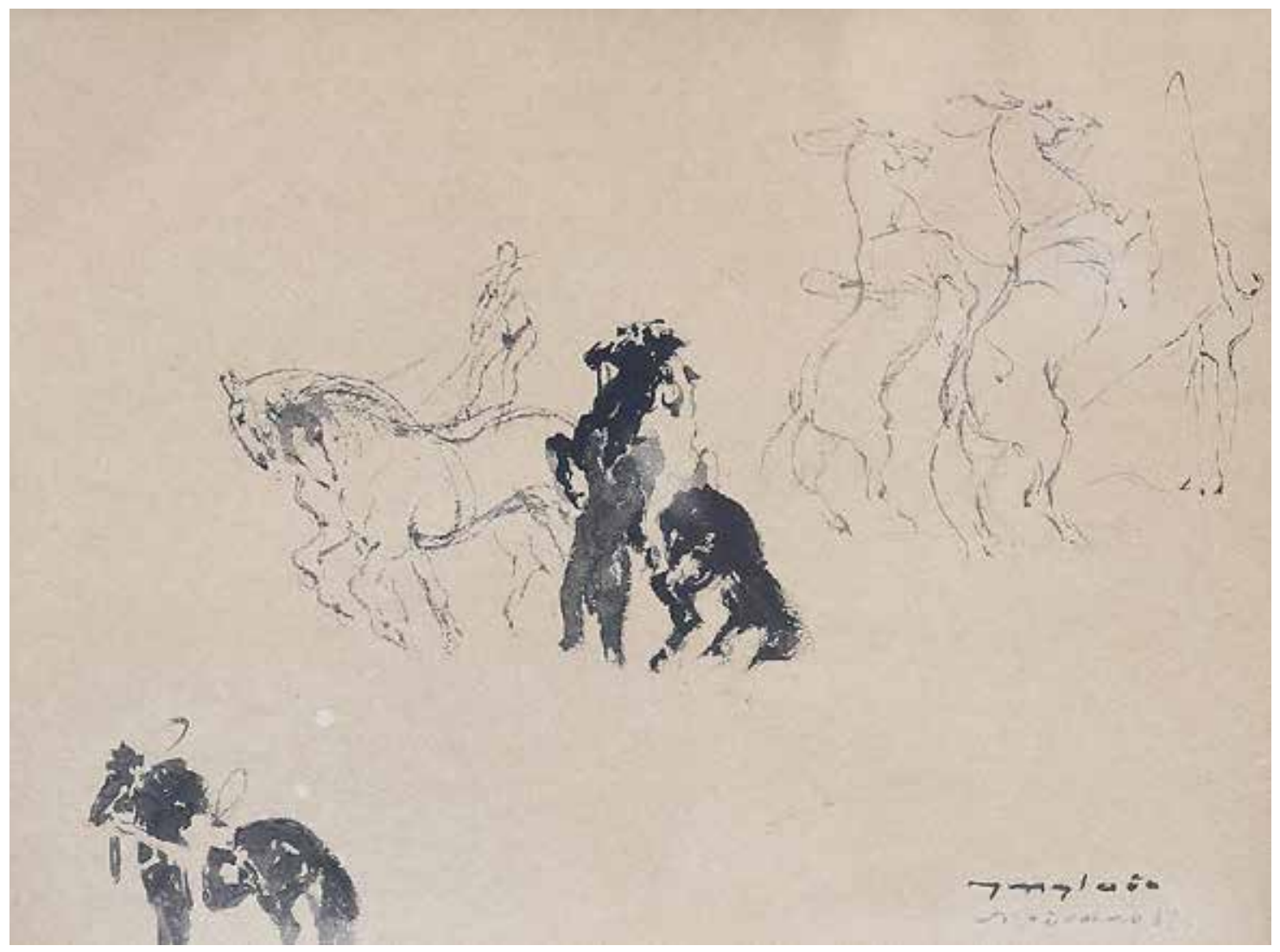

Figura 12.

Pere Ynglada, escena al circ Medrano de París, ca. 1920-1940. Tinta xinesa sobre paper. Col-lecció particular.

tal, tant de París com de Barcelona ${ }^{62}$. En efecte, ell va ser un dels pocs catalans que van arribar a reivindicar públicament amb entusiasme el valor de la col-lecció de Josep Mansana ${ }^{63}$. L'interès i les coneixences van fer que el mateix Ynglada comencés a comprar peces tant xineses com japoneses: porcellanes, ceràmiques celadon, caixetes kögo, netsuke, llibres i estampes xilogràfiques d'autors com Masayoshi i Hiroshige (figura Io), a més de, pintures tan antigues i modernes (figura II), que guardava amb cura i que compartia amb els amics ${ }^{64}$, com Junoy, Enric Cristòfol Ricart i Joaquim Sunyer:

Un dia Pere Ynglada, l'apassionat orientalista i colleccionador de petites grans meravelles, va trobar-se amb Joaquim Sunyer i no es va poder estar de fer-li un vehement elogi del netzké [netsuke], d'aquests petits objectes escultòrics que els japonesos porten penjant de la tabaquera pel gust d'acariciar-los amb els dits, d'endevinar-ne la forma amb plaer tàctil. Ynglada portava un d'aquests netzké a la butxaca, un pardalet arronsat, minúscula escultura tota roma de forms. Allargà la mà closa a l'amic pintor tot tancant els ulls i li digué: «Palpeu això». Quan Sunyer va trobar-se amb allò als dits va dir, amb l'aire més indife- rent: «Què és això? Una avellana?». Ynglada, esgarrifat, marxà posant-se les mans al cap ${ }^{65}$.

Enric C. Ricart, qui narrava aquesta anècdota, recordava les tardes senceres compartides a París amb Ynglada, al costat del qual acabava «aprenent sempre quelcom d'interessant dels japonesos antics» ${ }^{66}$. I com Ricart, Feliu Elias, Josep Maria Junoy i fins i tot Pablo Picasso. En ocasió d'una de les freqüents visites al taller del carrer de La Boétie de Picasso entre 1927 i 1928 com a intermediari de Gustau Gili i Gaziel per mirar d'emprendre l'edició il-lustrada de $L a$ Tauromàquia, Picasso va arribar a mostrar a Ynglada un dels primers llibres publicats al Japó sobre ell, a fi d'ensenyar-li com s'escrivia el seu nom en alfabet katakana ${ }^{67}$. Fem aquest apunt perquè és si més no curiós comprovar com $\mathrm{La}$ Tauromaquia (1959) va acabar naixent trenta anys més tard, just en el moment en què Picasso explorava amb més intensitat l'entusiasme per la pintura monocroma de tradició oriental que tant va atraure i marcar Ynglada ${ }^{68}$.

Al llarg de la dècada de 1920, Ynglada es va involucrar en diverses iniciatives per mirar de difondre l'art de l'Àsia Oriental a Catalunya. Segurament el projecte més ambiciós va ser l'organització d'una gran exposició d'art antic de la Xina, el 


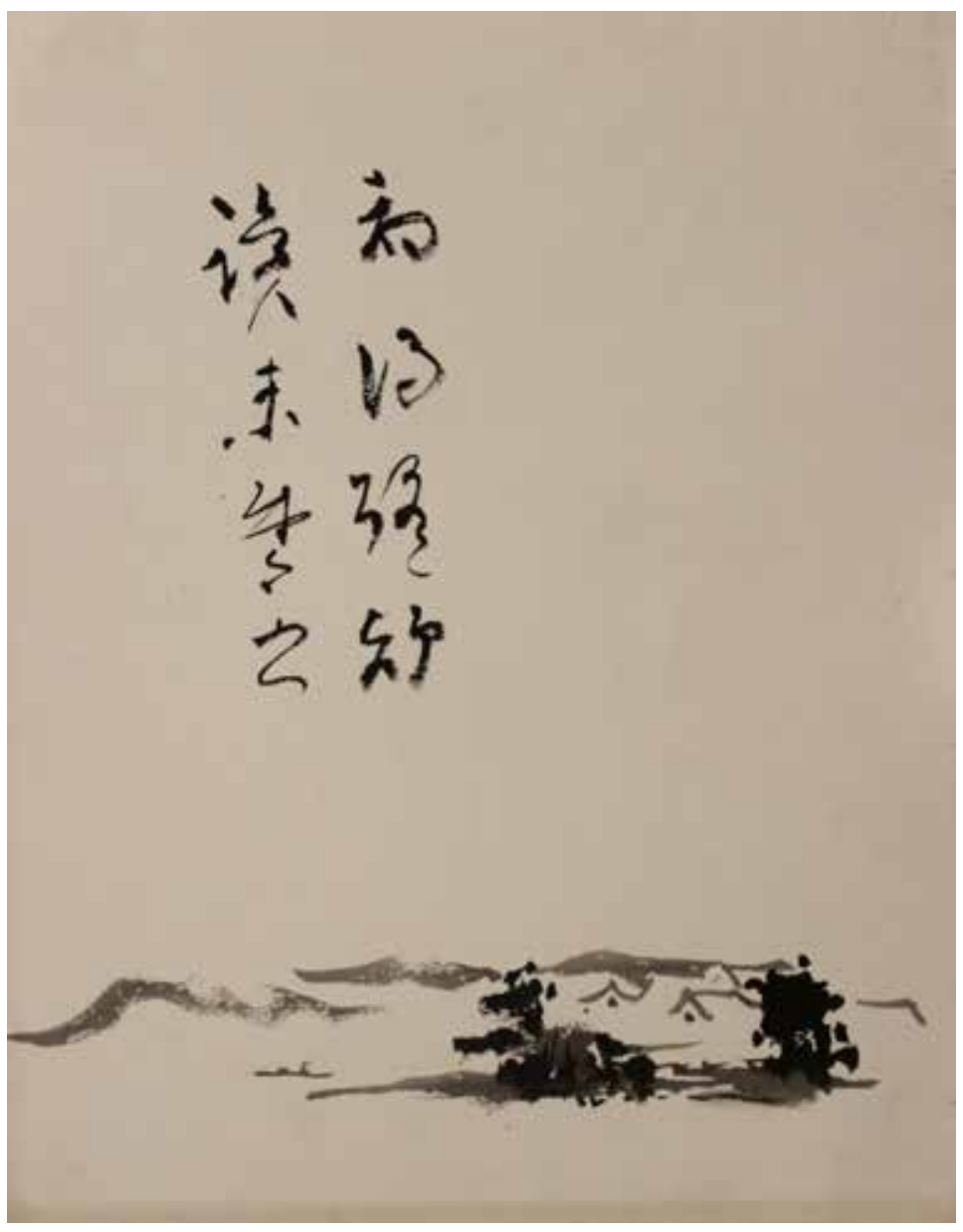

Figura 13.

Pere YNGLAdA, Paisatge amb cal-ligrafia, ca. 1920-1940. Cal-ligrafia atribuïda probablement a una mà japonesa. Museu Nacional d'Art de Catalunya, 157.942. Llegat Raimon Noguera, 1991.

Japó i Pèrsia preparada l'any I923 conjuntament amb Feliu Elias i amb l'adhesió de l'Ajuntament de Barcelona. L'exposició s'havia de celebrar en substitució de les habituals mostres d'art català a l'estranger $\mathrm{i}$ les d'art estranger annexes a l'Exposició de Primavera. Hom imaginava que seria «l'inici de l'indispensable Museu d'art extrem oriental» ${ }^{69}$, i a tal fi l'organització va comptar amb la col-laboració decidida i essencial de Charles Vignier i amb el sí d'importants col-leccionistes estrangers $^{70}$. Ynglada sempre lamentaria com, a causa del cop d'estat de Primo de Rivera, l'exposició va ser sobtadament aturada a l'últim moment pel general Losada ${ }^{71}$. Finalment, la mostra es va acabar celebrant dos anys més tard a París ${ }^{72}$.

\section{Copsar la vida}

Acabada la guerra, Ynglada, instal-lat des d'uns quants anys abans en una nova residència situada a la cantonada entre el carrer de Saint-Sénoch i el carrer Logier de París, va continuar mante- nint relació amb nombroses personalitats del món de l'art, des de companys de joventut com Picasso i Juan Gris fins a Theodor Duret i Charles Vignier. A més, a París va refermar l'amistat amb Joaquim Sunyer, Lluís Garriga Roig i Josep Maria Junoy. Uns quants anys més tard recordaria les llargues estades al taller de $\mathrm{Su}$ nyer, les contínues visites als espectacles de circ (figura r 2) i music-hall amb Junoy o bé els passejos i les converses amb Pla.

Durant uns quants anys, tant durant la dècada de i9ro com a inicis dels anys vint, Ynglada va mantenir el costum de concórrer amb molta freqüència al cinema i al music-ball, d'on li va sorgir la fal-lera del moviment $i$ on es va acostumar a prendre notes a vola ploma; apunts ràpids per copsar moments fugissers, deia ${ }^{73}$. Es tractava d'un interès pel moviment $i$ per les palpitacions de la vida que el va dur a fixar-se en els animals d'una manera quasi obsessiva fins al punt d'acabar-se especialitzant com a dibuixant de cavalls, mamífers, peixos i bestioles: "els animals salten, corren, inconscients de les línies que jo dibuixo. D'aquesta manera tinc davant els ulls un espectacle viu de debò» ${ }^{74}$. Captava els instants amb precisió i veloçment, però al mateix temps prenent-se el temps necessari per poder-ne captar la veritat: «per fer la pota d'un cavall o el morret d'un conill, hi passava a vegades cinc o sis dies», deia Pla amb una certa exageració literària ${ }^{75}$. Captava la vida tal com es feia a Orient i com ho havien fet, també, els impressionistes que tant admirava $^{76}$. En aquest punt, el pinzell i la tècnica de la tinta xinesa van oferir-li el mitjà òptim per preservar la frescor d'una vida que va ser copsada «com un Hokusai occidental»"

Per a Pere Ynglada l'estudi de la pintura monocroma antiga de tradició xinesa va ser l'autèntic punt de partida per explorar una tècnica que el va conduir a dominar el pinzell amb un traç enèrgic $i$ intel-ligent capaç de materialitzar l'atracció que sentia pels animals. Mirant enrere, les imatges de Belle Époque li semblaven impostades i poc sinceres, perquè aleshores, per fi, havia trobat un mitjà d'expressió amb el qual s'identificava profundament ${ }^{78}$. Josep Maria Junoy, que com a entusiasta de la poesia japonesa compartia uns gustos similars als d'Ynglada i Soldevila, afirmava:

[...] una obra mestra de pintura xinesa, d'una bona època - de l'època Tang o de l'època Song - representa i suggereix tot allò que pugui haver-hi de grandiós i de serenament reposant en la personalitat, diríem-ne impersonal. L'home no és el centre de la composició. L’ànima és escampada arreu, per les muntanyes, pels arbres, pels rierols, sense cap tendenciosa humana preferència ${ }^{79}$. 


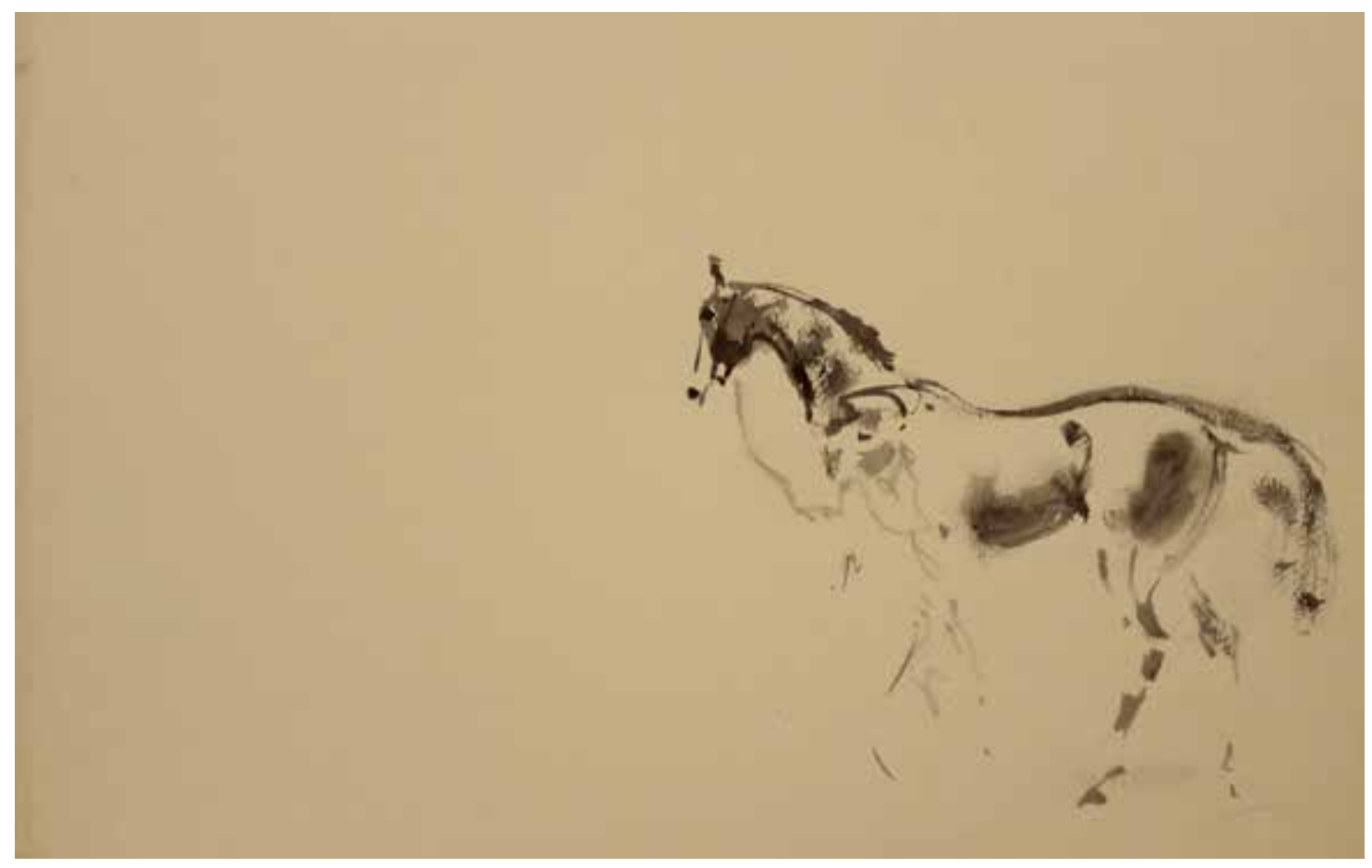

Figura 14.

Pere Ynglada, Cavall, ca. 1920-1940. Tinta xinesa sobre paper. Museu Nacional d'Art de Catalunya, 157.922. Llegat Raimon Noguera, 1991.

Junoy ho il.lustrava el maig de 1927 des de $L a$ Revista Nova amb la imatge d'una antiga pintura xinesa de la colllecció de Vignier, facilitada per Pere Ynglada ${ }^{80}$. El mateix Ynglada va prendre com a punt de partida moltes d'aquestes obres per representar paisatges i animals (figura I 3 ). L'observació calmada dels dibuixos que ens han arribat mostra com tots són diferents: estudis plens de matisos, jugant amb la indeterminació d'un espai aparentment buit i amb l'expressivitat del pinzell (figura I4). N'hi ha molts que són testimoni de com l'artista utilitzava el pinzell de maneres diverses, algunes vegades jugant amb les gradacions cromàtiques de la força dels traços negres per crear profunditat o bé per definir la silueta de cavalls $\mathrm{i}$ de persones evocant formes cal-ligràfiques. De fet, un dels aspectes menys explorats però més interessant de molts dibuixos d'Ynglada és veure com el traç de pinzell permetia la fusió entre pintura i escriptura ${ }^{81}$. Captivat per la cal-ligrafia oriental, va aprendre a transformar aquells grafismes llunyans fins a convertir-los en formes humanes $i$ animals que esdevenien l'últim estadi d'una cal-ligrafia personal: «dibujar es escribir», afirmava Ynglada, «y esto no solo en un sentido íntimo de expresión, sino incluso materialmente» (figura I 5$)^{82}$.

Feliç d'haver trobat el seu camí i un cop establert al barri de l'Étoile de París, a partir de l'any I92 I Ynglada va començar a exposar de manera continuada uns dibuixos que, de manera inalterable, es van mantenir fidels a l'estil desen-

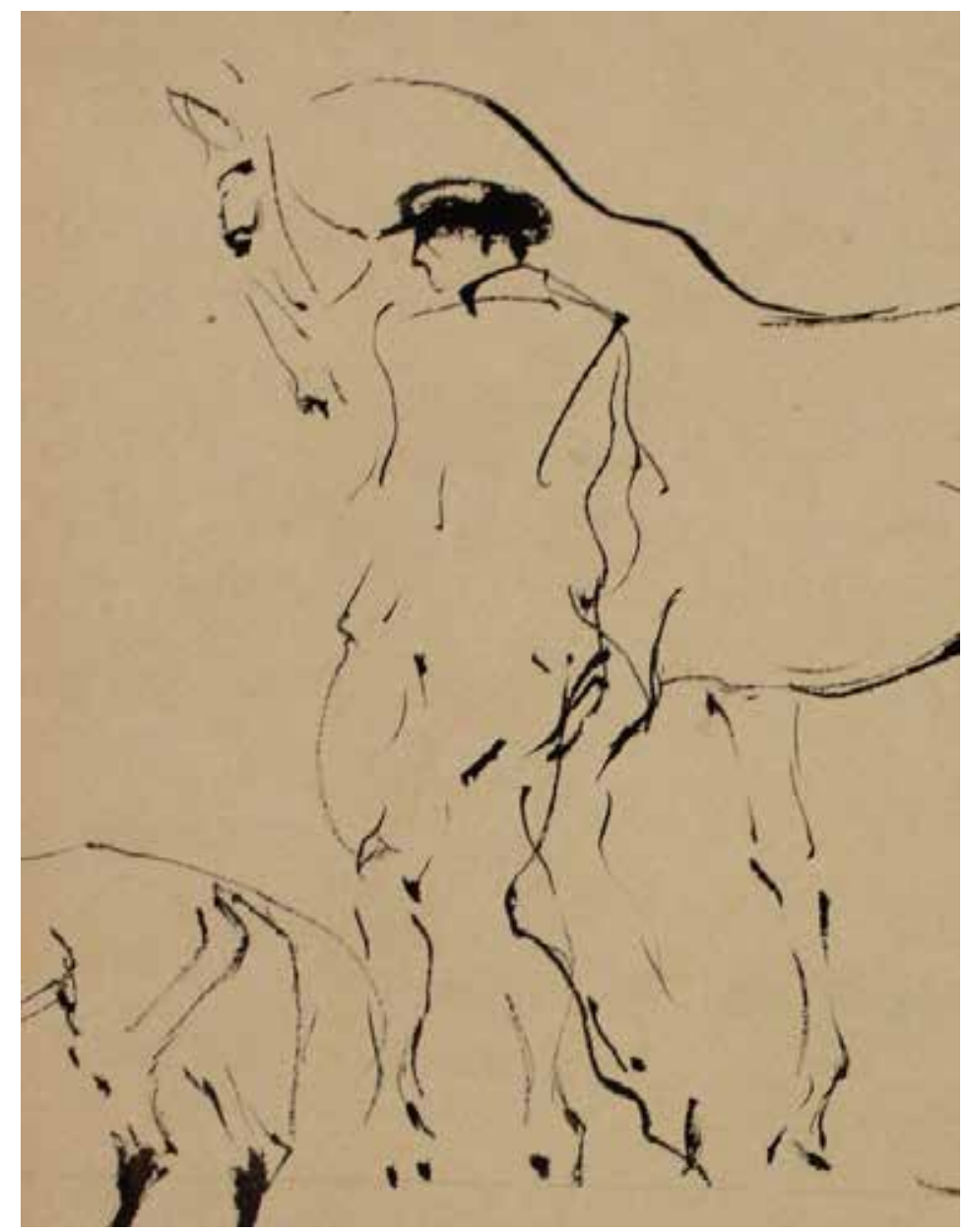

Figura 15.

Pere Ynglada, fragment de dibuix de traç cal-ligràfic, ca. 1920-1940. Tinta xinesa sobre paper. Museu Nacional d'Art de Catalunya, 157.903. Llegat Raimon Noguera, 1991. 
volupat al Jardí d'Aclimatació i a l'hipòdrom. Aquella manca d'interès per exposar d'anys anteriors es va transformar, aleshores, en una presència constant d'Ynglada a les exposicions. Així, al Saló de Tardor de Barcelona de I92 I, hi va participar amb un dibuix de cavalls de perfil, una escena de circ $\mathrm{i}$ un paisatge amb cavalls, mentre que a l'Exposició d'Art de l'any següent hi va intervenir amb quatre dibuixos més. Ynglada va presentar anualment dibuixos d'animals a les mostres que el grup Les Arts i els Artistes va celebrar a les Galeries Laietanes i a La Pinacoteca entre els anys I924 i I934, i també va exposar al Cercle de Belles Arts de Madrid l'any I926, a la Sala Vayreda d'Olot l'any I930, a les Galeries Syra l'any 1933, a la Fira del Dibuix del Poble Espanyol l'any I940 i també a tres exposicions destacades celebrades a La Pinacoteca, el maig de 1934, de I936 i de 1943, acompanyat de Lluís Mercadé i Josep Dunyach. Tampoc va descuidar l'exposició d'obres similars a París: a partir de 1925 , es va començar a presentar anualment al Saló de Tardor i, a partir de 1930, al Saló de les Tulleries, on l'Estat francès li va comprar un dibuix de peixos amb tinta xinesa ${ }^{83}$. En definitiva, l'autèntic Ynglada es va donar a conèixer entre $1920 \mathrm{i}$ I 940.

Ynglada mai va tenir la necessitat d'exposar i sempre es va mostrar reservat amb la seva obra. N'era tant de reservat que, poc abans de morir, va expressar en una nota mecanografiada el desig que cap de les seves obres i objectes personals acabessin lliurats als museus del Barcelona ${ }^{84}$. També, al llarg dels anys, va rebre nombroses peticions de colllaboració, especialment per il-lustrar llibres que mai van acabar sortint a la llum: si el novembre de 1927 es disposava a il-lustrar una Elegia al Circ que preparava un escriptor catală ${ }^{85}$, l'estiu de 1928 confirmava a Gustau Gili que il.lustraria un llibre de faules ${ }^{86}$, mentre que a d'altres, com a Junoy, els prometé la il.lustració d'un dels seus llibres de capçalera: Histoires Naturelles, de Jules Renard ${ }^{87}$. Cap d'aquestes obres, com tampoc un llibre il-lustrat dedicat al cavall ${ }^{88}$, es van arribar a publicar ${ }^{89}$.

Excepte en el cas de les il-lustracions d'inicis de segle, la immensa majoria dels dibuixos fets entre I910 i I 940 no estan datats, i això que se'n conserven diversos milers. Aquest fet dificulta la catalogació precisa de la seva obra, però, tanmateix, no resulta un problema per valorar una trajectòria que va evolucionar de manera clara fins a convertir aquell primer dibuixant $\operatorname{del}_{j} \mathrm{Cu}$ Cut! i La Esquella de la Torratxa en un enamorat dels cavalls i un apassionat de la pintura de la Xina i del Japó. Un viatge que el va conduir cap a les arts d'Orient $\mathrm{i}$ que el va submergir cap a una estètica que va mantenir viva fins als últims anys. Passats uns dos anys de la fi de la Guerra Civil espanyola, en morir el seu germà Artur, Pere Ynglada va decidir traslladar-se de manera definitiva a Barcelona, a la Ronda de Sant Pere 22, per ocupar-se, juntament amb Frederic Barris, de la gestió de la ferreteria familiar, de la qual mai s'havia desprès del tot. Van ser uns últims anys discrets i viscuts en serenitat amb Georgette i amb els seus amics ${ }^{90}$. Finalment, després de la defunció de l'esposa l'any 1955, Ynglada es va apagar i va acabar morint el 17 de febrer de 1958 , a l'edat de 77 anys. 
1. Exposición de dibujos de Pedro Ynglada: Catálogo, Barcelona, Palau de la Virreina, 1959.

\section{V. Durá (2012), Premi Interna-} cional de Dibuix Ynglada-Guillot 50è aniversari, Barcelona, Reial Acadèmia de Belles Arts de Sant Jordi. L'Arxiu Nacional de Catalunya conserva bona part de la documentació referent al llegat d'Ynglada i la Fundació Ynglada-Guillot dipositada pel notari Raimon Noguera (ANC1-223-06.47). El mateix arxiu també conserva el manuscrit original de Carles Soldevila, titulat Parece que fue ayer: Recuerdos y opinions de Pedro Ynglada (ANC194-14). Vegeu C. Soldevila (1959), Records $i$ opinions de Pere Ynglada, Barcelona, Aedos.

3. Esther Tusquets va tenir ocasió de consultar escrits dels últims anys que Pere Ynglada conservava al pis de la Ronda de Sant Pere número 22, guardats pel Dr. Perpiñá Robert i que actualment es consideren perduts. Vegeu E. Tusquets (1960), Pedro Ynglada: La expresión de lo fugaz, Barcelona, Universitat de Barcelona, i F. FontBona (2012), «Pere Ynglada i el seu món», a V. Durà, Premi Internacional de Dibuix Ynglada-Guillot 50è aniversari, Barcelona, Reial Acadèmia de Belles Arts de Sant Jordi, p. 13-20.

4. Vegeu també J. MercaderMiret (1980), «El nostre Pere Ynglada i Sallent», Miscel-lània Penedesenca, vol. 3, p. 91-100.

5. C. Soldevila (1959), Records $i$ opinions..., op. cit., p. 13.

6. C. Soldevila (1959), Records i opinions..., op. cit., p. 25-31, i J. Pla (1970), «Pere Ynglada, dibuixant», Obra Completa. Volum XVII. Retrats de passaport, Barcelona, Destino, p. 275.

7. C. Soldevila (1959), Records i opinions..., op. cit., p. 32-37, i J. Mercader-Miret (1980), «El nostre Pere Ynglada...», op. cit., p. 94.

\section{J. M. F. (1901), «Exposición} comarcal», La Correspondencia de España, núm. 15.945 (3 d'octubre), p. 2.

9. J. Pla (1963), «Pedro Ynglada dibujante», Destino, núm. 1349 (15 de juny), p. 35. Vegeu també J. Pla (1970), «Pere Ynglada...», op. cit., p. 274-283.

10. Josep Pla, en canvi, el definia com «un pur snob». Vegeu J. PLA
(1969), Obra Completa. Volum XII. Notes disperses, Barcelona, Destino, p. 49.

11. La Veu de Catalunya, núm. 3.264, 23 de maig de 1908 (ed. de vespre), p. 1.

12. J. Pla (1963), «Pedro

Ynglada...», op. cit., p. 35.

13. C. Soldevila (1959), Records $i$ opinions..., op. cit., p. 150.

Respecte a l'auca dedicada a la vida de Lluís Garriga Roig, amic íntim de Pere Ynglada, dibuixada per Smith i acompanyada de rodolins de Maseras, vegeu J. CASAMARTINA I Parassols (2017), Ismael Smith: La bellesa $i$ els monstres, Barcelona, Museu Nacional d'Art de Catalunya, p. 88, i E. Vallès i I. Cendoya (2016), «Picassos, nonells i sunyers per a Barcelona: Contingut i vicissituds del llegat de Lluís Garriga Roig», a B. BASSEgoda i I. Domènech (eds.), Col-leccions, antiquaris, falsificadors i museus: Noves dades sobre el patrimoni artístic de Catalunya al segle $X X$, Memoria Artium, 21, p. 157-169.

14. Centre de Documentació i Recerca del Museu Picasso, Fons Joan Vidal Ventosa, FVV/ TEX/7/222. Carta de Pere Ynglada a Joan Vidal Ventosa del 21 de gener de 1907. F.M. (1926), «El arte catalán en Madrid», El Liberal, núm. 16.405 (16 de gener), p. 2, i J.M. Junoy (1954), «Entre la vida y el recuerdo. 70 , rue des Martyrs», Destino, núm. 900 (6 de novembre), p. 24-25.

15. Molts dels dibuixos originals d'aquestes il-lustracions provenen de la col-lecció Agell (1962) i es conserven al Gabinet de Dibuixos i Gravats del Museu Nacional d'Art de Catalunya.

16. J. Navarro Costabella (1928), «Artistes catalans: Paraules de Pere Inglada», La Veu de Catalunya, núm. 9.882 (31 de gener), p. 7.

\section{J.M. DE S. (1930), «El}

"Guayaba”", Mirador, núm. 54 (6 de febrer), p. 3, i R. Torrella (1993), «El Guayaba de Joan Vidal Ventosa», Revista de Catalunya, núm. 71, p. 99-112.

18. El Museu Nacional conserva un retrat de Pere Romeu dibuixat per Ynglada i publicat a $L a$ Esquella de la Torratxa el 17 de juny de 1904 (MNAC, núm. inv. 41.308), així com diversos dibuixos i postals fruit de la relació personal entre Ynglada i Garriga Roig.
19. La fotografia, en la qual també apareix retratat Ramon Reventós, pertany al fons dels museus municipals. Se'n conserven originals tant al Museu Picasso de Barcelona com a l'Arxiu Fotogràfic de Barcelona. Vegeu Josep PaLau I Fabre (1980), Picasso Vivent 18811907: Infantesa i primera joventut d'un demiürg, Barcelona, Polígrafa, p. 438.

20. Algunes de les postals enviades per Pere Ynglada a El Guayaba es conserven al fons de Vidal Ventosa del Museu Picasso de Barcelona. Vegeu C. Soldevila (1959), Records i opinions..., op. cit., p. 127.

21. J. Navarro Costabella (1928), «Artistes catalans...», op. cit., p. 7.

22. J.B. FÉcit (1906), «De l'art que belluga: Gargots y coloraines», ¡Cu-Cut!', any 5, núm. 214 (28 de juny), p. 173.

23. «Noves», Joventut, núm. 333

(28 de juny de 1906), p. 414.

24. Si bé va guardar un molt bon record del seu pas per El Guayaba, en canvi, Ynglada sempre va despatxar amb rapidesa $i$ va passar de puntetes per sobre d'aquesta primera etapa prolífica com a il-lustrador de revistes: «pequeños pecadillos que afortunadamente no dejaron rastro». Vegeu J. Navarro Costabella (1928), «Artistes catalans...», op. cit., p. 7, i J.T. (1940), «En el taller de los artistas con P. Ynglada», Destino, núm. 158 (27 de juliol), p. 11.

\section{J. Navarro Costabella} (1928), «Artistes catalans...», op. cit., p. 7.

26. Centre de Documentació i Recerca del Museu Picasso, Fons Joan Vidal Ventosa, FVV/ TEX/7/222. Carta de Pere Ynglada a Joan Vidal Ventosa del 21 de gener de 1907.

27. Ynglada i Elias van mantenir una llarga correspondència, de la qual se'n conserven 74 postals enviades per Ynglada a Elias a partir del novembre de 1908, on es posa de manifest la relació personal i professional entre els dos artistes (Biblioteca de Catalunya, Fons Ramon Borras, Capsa Y2).

28. E. Tusquets (1960), Pedro Ynglada..., op. cit., p. 60.

29. J.M. JunOY (1952), «Entre la vida y el recuerdo: Un taller en la desaparecida Riera de San Juan», 
Destino, núm. 779 (12 de juliol), p. 5-7.

30. L'Snow, que va arribar a ser la portada de la revista Los Deportes en el seu número del 15 de juny de 1910, apareix a moltes de les fotografies, dibuixos, il-lustracions de revistes i descripcions d'Ynglada.

31. Aquest canvi de rumb es fa palès al capítol que Junoy dedica al llibre Arte $\mathcal{E}$ Artistas. Vegeu J.M. Junoy (1912), Arte E Artistas, Barcelona, Llibreria de L'Avenç, p. 37-40.

32. J. Navarro Costabella (1928), "Artistes catalans...», op. cit., p. 7. Vegeu també V. SOLÉ DE Sojo (1914), «Pere Inglada», $L a$ Patria, núm. 1 (22 de maig), p. 1-2.

33. Tot i haver fixat la residència a París, Ynglada va passar moltes temporades a Barcelona participant a les llargues tertúlies de la penya de l'Ateneu, amb Carles Soldevila, Josep Maria de Sagarra, Eugeni d'Ors, Quim Borralleras, Raimon Noguera, etcètera. Vegeu J.M. DE SAGARRA (1958), «Pedro Ynglada», La Vanguardia, núm. 28.532 (28 de febrer), p. 5; C. Soldevila (1958), «Pedro Ynglada», Destino, núm. 1073 (1 de març), p. 2728, i E. Tusquets (1960), Pedro Ynglada..., op. cit., p. 27-30.

34. La Esquella de la Torratxa, núm. 1693 (9 de juny de 1911), p. 359.

35. La Publicidad, núm. 12.030 (9 de setembre de 1912), p. 1.

36. J.M. Junoy (1912), Arte E Artistas, Barcelona, Llibreria de L'Avenç, p. 40.

37. El prospecte de la revista anuncia la participació, entre d'altres, de Pere Ynglada, si bé la curta durada de la publicació va fer que no hi acabés col-laborant. Així mateix, es conserven unes petites illlustracions d'Ynglada en les quals el dibuixant, identificat com a «Yda», apareix agafat de la mà de la revista Picarol (MNAC, núm. inv. 65.749).

38. Xenius (1914), «Glosari: Pere Ynglada, noucentista», La Veu de Catalunya, núm. 5.396 (15 de maig), p. 1.

39. E. Tusquets (1960), Pedro Ynglada..., op. cit., p. 78.

40. Van aparèixer articles comentant l'exposició a L'Esquella de la Torratxa, ;Cu-Cut!, La Patria, Catalunya i a la Revista
Nova. L'única crítica lleugerament discrepant la va publicar el $; \mathrm{Cu}$ Cut!. Bene (1914), «L'art que belluga», ; Cu-Cut!, any 13, núm. 30 (28 de maig), p. 360.

41. A. Plana (1914), «L'art d'en Pere Ynglada», Catalunya: Revista Setmanal, núm. 22 (30 de maig), p. 343; R. JORI (19I 5), «En Pere Inglada», Vell i Nou, núm. 4 (3 d'abril), p. 2-3, i V. Solé DE SOJO (1914), «Pere Inglada», La Patria, p. 1-2.

42. Quatre dels dibuixos exposats van ser comprats per Frederic Barris i van ser presentats l'any següent a Sabadell, a l'Exposició d'Art Nou Català. Vegeu J. SACS (1914), «Les miniatures d'en Pere Inglada», Revista Nova, núm. 11 (20 de juny), p. 6-7 i J. L. Martín i Berbois (2015), Cent anys d'Art Nou Català, Sabadell, Museu d'Art de Sabadell, p. 78-80.

43. J. Navarro Costabella (1928), «Artistes catalans...», op. cit., p. 7.

44. Arxiu Nacional de Catalunya, ANC1-223, fons Raimon Noguera, 0647.01 (1939).

45. A tall d'exemple vegeu els dibuixos del Museu Nacional 65.762 i 65.772 .

46. Molts d'aquests van ser donats el 1959 pel notari Noguera al Museu Nacional d'Art de Catalunya (MNAC 65.761-65.775). Uns altres, en canvi, encara es poden trobar a la venda a diversos portals d'internet.

47. Vell i Nou, núm. 10 (1 d'octubre de 1915), p. 16; Rémy DE Gourmont (1918), Les idées du Jour (Mai 1915 - Septembre 1915), París, Georges Cres et Cíe, p. 179; André BLUM (I92I), «La caricature de guerre a l'étranger», Gazette des Beaux-Arts (juliol), p. 180-171, i B. (1917), «Germania», Iberia, núm. 94 (20 de gener), p. 3.

48. Molts dels dibuixos de guerra, algunes de les il-lustracions d'Iberia i les notes preses al front es conserven al Museu Nacional d'Art de Catalunya, fruit de la donació del notari Raimon Noguera. Vegeu P. YngladA (1916), «Los caminos de la muerte y de la gloria...», Iberia, núm. 42 (22 de gener), p. 8-10; P. YNGLAdA (1916), «Los caminos de la muerte y de la gloria... II», Iberia, núm. 43 (29 de gener), p. 8-10; Iberia, núm. 69 (29 de juliol de 1916), p. 7, i La Publicidad, núm. 13.616 (12 de febrer de 1917), p. 5.
49. La Publicidad, núm. 13.889 (12 de desembre de 1917), p. 1, i Iberia, núm. 155 (30 de març de 1918), p. 7-14. Vegeu algunes de les notes originals aportades pel notari Noguera al Museu Nacional (MNAC 67.732-67.758, MNAC 157.947-157.954).

50. ANC1-223, fons Raimon Noguera, 0647.01 (1939).

51. Flama (1924), «Pere Inglada, dibuixant animalista», Gaseta de les Arts, núm. 6 (1 d'agost), p. 4-5.

52. Com a mostra d'aquest interès per l'avantguarda, Enric C. Ricart també recordava l'experiència viscuda al Festival Dada de la Salle Gaveau del 26 de maig de 1920, juntament amb Ynglada, Lluís Garriga Roig, Quim Borralleras i Lluís Mercadé. Vegeu Enric CRistòfol Ricart (2003), Memòries (ed. a cura de Ricard Mas), Barcelona, Parsifal Edicions, p. 128.

53. A. Maseras (octubre 1933-juliol 1934), «Pere Ynglada, dibuixant animalista», $A r t$, vol. 1, p. 253.

54. «Artistes Catalans: Paraules de Pere Inglada», La Veu de Catalunya, núm. 9882 (31 de gener de 1928), p. 7. L'impacte d'aquesta descoberta es fa palès amb l'autoretrat que Ynglada va presentar aquell mateix 1907 a Exposición de auto-retratos de artistas españoles celebrada a Barcelona, en el qual l'artista apareix acompanyat del seu gos i vora una estampa d'Utamaro. Agraeixo la referència a Juan C. Bejarano.

55. C. Soldevila (1959), Records $i$ opinions..., op. cit., p. 47.

56. La Esquella de la Torratxa, núm. 1693 (9 de juny de 1911), p. 359.

57. Segurament Junoy es referia a la pintura sumi-e, que definia a peu de pàgina com a «género especial de dibujo, inventado por el pintor chino Siu-hi [Su Shi?], que vivió en el siglo $\mathrm{x}$ de nuestra Era: procedimiento que fué luego muy empleado por los artistas chinos y japoneses». Vegeu J.M. Junoy (1912), Arte E Artistas, Barcelona, Llibreria de L'Avenç, p. 39-40.

58. Xenius (1914), Exposició Ynglada, Barcelona, Fayans Català.

59. J. SACs (1914), «Les miniatures...», op. cit., p. 6-7. 
60. Flama (1924), «Pere Inglada...», op. cit., p. 4; C. Soldevila (1959), Records i opinions..., op. cit., p. 47; E. Tusquets (1960), Pedro Ynglada..., op. cit., p. 66, i Biblioteca de Catalunya, fons Ramon Borras, Capsa Y2, postal sense datar, molt probablement de 1908, de Pere Ynglada a Feliu Elias.

61. A. Plana (1934), «Arte y artistas», La Vanguardia, núm. 21.904 (23 de maig), p. 9, i ConneIsseur (1934), «Pedro Ynglada y los pintores animalistas», Revista Ford, núm. 30 (agost), p. 768.

62. Biblioteca de Catalunya, fons Ramon Borras, Capsa Y2. Postal de Pere Ynglada a Feliu Elias de l'abril de 1922.

63. Myself (1927), «La col·lecció Mansana. Art extrem-oriental», D'ací i d'allà, núm. 111 (març), p. 82-84, i Japonisme: La fascinació per l'art japonès, Barcelona, Obra Social La Caixa, 2013, p. 182-185.

64. Amb els anys, la col-lecció Ynglada es va acabar perdent $\mathrm{i}$ actualment tan sols en coneixem l'existència de peces menors com ara alguna pintura $\mathrm{i}$ alguns dels àlbums i de les estampes japoneses $i$ xineses que va regalar l'any 1932 a l'actual Museu Nacional. Igualment, la Biblioteca Joaquim Folch i Torres del Museu conserva també una part de la interessant biblioteca de Pere Ynglada (llegat de 1959).

65. Enric CRISTÒfol RicART (2003), Memòries, op. cit., p. 84.

66. Entic Cristòfol Ricart (2003), Memòries, op. cit., p. 140 141.

67. C. Soldevila (1959), Records i opinions..., op. cit., p. 169, i C. Rafart Planas (2016), Pablo Picasso i els editors Gustavo Gili: Escrits des de Barcelona, Barcelona, Publicacions de l'Abadia de Montserrat, p. 90-103.

68. R. Bru i K. Matsuda (2016), «Identitats llunyanes: Diàlegs, influències i confluències entre Pablo Picasso i l'art japonès», Picasso i identitat: 3er congrés internacional, Barcelona, Museu Picasso (28 d'abril), recuperat el 15 de juny de 2017, de <http:// museupicassobcn.org/congresinternacional/ca/bru-matsuda/>.

69. J. SACs (1930), «Al marge d'una exposició a Londres: L'art persa», Mirador, núm. 98 (18 de desembre), p. 7.

70. L'amistat entre Ynglada i Vignier es va consolidar un cop acabada la guerra mundial. Durant els anys vint les trobades a París van ser freqüents i l'any 1928 Ynglada va acompanyar Vignier i Joseph Hackin, director del Museu Guimet, a Barcelona. Vegeu «Exposició d'Art Extrem-oriental», La Veu de Catalunya, núm. 8.454 (5 de juliol de 1923), p. 9.

71. C. Soldevila (1959), Records $i$ opinions..., op. cit., p. 128-130.

72. «Una Exposició d'Art Oriental anterior al segle xIv», Gaseta de les Arts, núm. 26 (1 de juny de 1925), p. 1-4, i Charles Vignier (1925), Catalogue de l'exposition d'art oriental: Chine-Japon-Perse, París, Chambre Syndicale de la Curiosité et des Beaux-Arts, n. 1118.

73. J. Navarro Costabella (1928), "Artistes catalans...», op. cit., p. 7, i A. MASERAS (octubre 1933-juliol 1934), «Pere Ynglada...», op. cit., p. 253.

74. J. Navarro Costabella (1928), «Artistes catalans...», op. cit., p. 7.

75. J. Pla (1969), Obra Completa. Volum XII. Notes disperses, Barcelona, Destino, p. 50.

76. Agraïm a Fernando PeripñáRobert la possibilitat de llegir les notes inèdites del Dr. Vilardell en relació amb les memòries del Dr. Perpiñá Robert i la seva amistat amb Pere Ynglada.

77. J. Quintana (1925)

«Exposició de les Arts i els Artistes", La Veu de Catalunya, núm. 3.960 (26 de febrer), p. 3.

78. E. Tusquets (1960), Pedro Ynglada..., op. cit., p. 103-109.

79. Josep Maria Junoy (1925), "Orient? Occident?», Revista de Catalunya, núm. 14 (agost), p. 157.

80. «Pintura xinesa antiga», $L a$ Nova Revista, vol. II, núm. 5 (maig de 1927), làmina $1, i$ «Orient $i$ extrem-Orient», La Nova Revista, vol. v, núm. 19 (juliol de 1928).

81. J.M. Junoy (1945), «Caballos de realidad y de ensueño», $L a$ Vanguardia Española, núm. 24.733 (12 de desembre), p. 3.

82. A. Plana (1934), «Arte y artistas», La Vanguardia, núm.
21.904 (23 de maig), p. 9, i J.T. (1940), «En el taller de los artistas con P. Ynglada», Destino (27 de juliol), p. 11.

83. L'any 1938, a més, en plena guerra civil espanyola, Ynglada també va participar al Salon des XXVI Lettres de l'Alphabet, de Lieja. Vegeu M. GIFREDA (1930), «Pere Ynglada», Mirador, núm. 83 (28 d'agost), p. 7, i E. TusQuets (1960), Pedro Ynglada..., op. cit.

84. V. Durá (2012), Premi

Internacional..., op. cit., p. 23.

L'adquisició i la donació Plandiura (1932), el llegat de Lluís Garriga

Roig (1940), el de Rossend Partagàs (1945), la donació i el llegat de Raimon Noguera (1959 i 1991), així com l'adquisició Agell, han permès que el Museu Nacional disposi actualment d'un conjunt de més de 2.000 dibuixos de Pere Ynglada. Agraeixo a Mercè Saura que m'hagi facilitat la consulta de tot aquest fons, conservat al Gabinet de Dibuixos i Gravats.

85. La Nova Revista, núm. 10 (octubre de 1927), p. 192.

86. J. Navarro Costabella (1928), «Artistes catalans...», op. cit., p. 7. Centre de Documentació i Recerca del Museu Picasso, Fons Editorial Gustavo Gili, FEGG/TEX/1/19, FEGG/TEX/1/21, FEGG/ TEX/1/22, FEGG/TEX/1/38.

87. José María Junoy (1935), «Los animales y la literatura», La Vanguardia, núm. 22.178 (10 d'abril), p. 9.

88. E. Tusquets (1960), Pedro Ynglada..., op. cit., p. 95.

89. L'única petita excepció seria la que va anotar a les seves memòries Josep Maria de Sagarra. Sagarra, amb qui Ynglada compartia les tardes a la penya de l'Ateneu, li va encarregar l'any 1914 un petit dibuix de dos cérvols per la justificació de tiratge del seu El primer llibre de poemes, il-lustrat per Josep Aragay. Vegeu J.M. DE SAGARRA (1967), «Memòries», Obres Completes: Prosa, Barcelona, Selecta, p. 1232.

90. Després de l'exposició de la primavera de 1943 a La Pinacoteca, amb Dunyach i Mercadé, l'obra d'Ynglada només va tornar a ser exposada dues vegades més, el febrer de 1946, a l'Exposición de dibujos de prestigiosos artistas de nuestra pintura de las Galeries Franquesa, i l'any 1955, a l'Exposición de Arte Contemporáneo Español, organitzada per l'Ajuntament de Conca. 
